BNL--28073-Rev.A

DE87 003206

\title{
REQUIREMENTS AND GUIDDELINES FOR NSLS EXPERIMENTAL BEAM LINE VACUUM SYSTEMS Revision A
}

\author{
C. Foerster, H. Halama and W. Thomlinson \\ October 1986
}

\author{
Original Document - BNL 28073 \\ J.B. Godel and J.C. Schuchman \\ July 1980
}

\section{DISCLAIMER}

This report was prepared as an accuunt of work sponsored by an agency of the United States Government. Neither the United States Government nor any agency thereof, nor any of their employees, makes any warranty, express or implied, or assumes any legal liability or responsibility for the accuracy, completeness, or usefulness of any information, apparatus, product, or process disclosed, or represents that its use would not infringe privately owned rights. Reference herein to any specific commercial product, process, or service by trade name, trademark, manufacturer, or otherwise does not necessarily constitute or imply its endorsement, recommendation, or favoring by the United States Government or any agency thereof. The views and opinions of authors expressed herein do not necessarily state or reflect those of the United States Government or any agency thereor.

\author{
Research Supported by the \\ OFFICE OF BASIC ENERGY SCIENCES \\ U.S. DEPARTMENT OF ENERGY \\ WASHINGTON, D.C.
}

NATIONAL SYNCHROTRON LIGHT SOURCE

BROOKHAVEN NATIONAL LABORATORY

Associated Universities, Inc.

Under contract No. DE-ACO2-76CH00016 with the

United States Department of Energy 
I. INTRODUCTION

II. BEAM LINE FRONT ENDS

II.A UHV Gate Yalve

II. B Fast Valve

II.C Fast Valve Sensors

III. VACUUM INTERLOCKS

IV. GUIDELINES FOR UHV BEAM LINE VACUUM SYSTEMS

IV.A Materials

IV.B Vacuum Hardware - Pumps, Valves, Flanges

IV.C Acoustic Delay Lines and Beam Line Fast Valves

IV.D Instrumentation

IV.E Fabrication and Testing

IV.F NSLS Cleaning Facility

V. DESIGN REVIEW

VI. ACCEPTANCE TESTS

\section{APPENDICES}

A. Acoustic Delay Line

Fast Valve Sensor

B. NSLS Vacuum Standards

SLS-07.10-6-1 Tentative Standards of the American Vacilum Society (Only Table of Contents Provided)

NSLS Technical Specifications

SLS-07.12-1-1 Cleaning Procedures for Vacuum Components and Hardware

SLS-07.12-2-1 Cleaning and Fabrication of Welded Bellows Assemblies

SLS-07.13-1-1 Thermister Gauge, Atmosphere to 1 Micron

SLS-07.13-2-1 Thermister Gauge, Atmosphere to 1 Micron

SLS-07.13-3-1 Ion Gauge, Cold Cathode, $10^{-3}$ to $10^{-8}$ Torr

SLS-07.13-4-1 Ion Gauge, Hot Filament, $10^{-4}$ to $10^{-11}$ Torr

SLS-07.14-1-1 UHV Bakeable Flanges (Conflat)

SLS-07.14-4-1 Copper Gaskets for Conflat Flanges

SLS-07.14-5-1 High Strength Bolts for Conflat Flanges

D. NSLS Procedures

SLS-07-19-12-1 Vacuum Procedure to Open VUV or X-ray Beam Line Front End Valve

SLS-07.19-4-1 Baking Out VuV or X-ray Storage Ring 


\section{INTRODUCTION}

A typical beam line, shown in Figure 1, is comprised of an assembly of vacuum valves and shutters referred to as a "front end", optical elements to monochromatize, focus and split the photon beam, and an experimental area where a target sample is placed into the photon beam and data from the interaction is detected and recorded.

Experimental beam lines share a common vacuum with storage rings. This is especially true on the VUV storage ring where for almost all experiments, windows will not be used. For the shorter wavelength, more energetic photons in the $x$-ray ring, beryllium windows may be used at various beam line locations so that the monochromator, mirror box or sample chamber may be used in a helium atmosphere or rough vacuum. The window separates ring vacuum from the atmosphere in downstream beam line components.

The stored beam lifetime in the storage rings and the liaintenance of desirable reflection properties of optical surfaces depend upon hydrocarbon-free, ultra-high vacuum systems. Storage ring vacuum systems will operate at pressures of $1 \times 10^{-10}$ Torr without beam and $1 \times 10^{-9}$ Torr with beam. Systems are free of hydrocarbons in the sense that no pulups, valves, etc. containing organics are used. Components are all-metal, chemically cleaned and bakeable. To the extent that beam lines share a common vacuum with the storage ring, the same criteria will hold for beam line components. The design philosophy for NSLS beam lines is to use all-metal, hydrocarbon-free front end components and recommend that experimenters use this approach for common vacuum hardware downstream of front ends. 0-ring-sealed valves, if used, are not permitted upstream of the monochromator exit aperture. It will be the responsibility of users to demonstrate that their experiment will not degrade the pressure or quality of the storage ring vacuum. As a matter of operating policy, all beam lines will be monitored for prescribed pressure and the contribution of high mass gases to this pressure each time a bean line is opened to ring vacuum. 
II. FRONT ENDS

Each beam port front end contains a $150 \mathrm{~mm}$ ( 6 in.) diameter Granville-Phillips (G-P) or VAT, all-metal gate valve and a BNL-designed fast valve with a $14 \times 140 \mathrm{~mm}$ aperture. The gate valve is the primary vacuum isolation valve between the storage ring and the beam line. The fast-acting valve, which closes' (but does not seal) in less than 8 milliseconds is used to intercept a pressure wave of atmospheric air from an accidental break in the beam line vacuum envelope. The gate valve is pneumatically closed and sealed in approximately two seconds.

All front ends will be designed, fabricated, installed and maintained by the NSLS. All vacuum interlocks on beam line components supplied by experimenters will use MSLS designs and/or specifications. Electrical connections between vacuum interlocks and front end components will be made and tested by NSLS staff members.

Front ends will be fitted with a hot filament ionization gauge to measure pressure, and a residual gas analyzer (RGA) head with a RF generator on a flanged valve connection. Spectrographic analysis of the residual gas will be done for each new experiment before the UHV valve is opened and then either continuously or intermittantly during operation. The frequency will be determined by the NSLS scientific coordinator in order to monitor changes in the partial pressure of the gas constituents.

\section{II.A UHV Gate Valve (Granville-Phillips or VAT Valve)}

The Granville-Phillips valve has a lifetime of approximately 2000 closures, after which the valve must be removed and replaced and the storage ring let up to boil-off $\mathrm{N}_{2}$. The VAT valve is larger and heavier than the G-P valve and has a lifetime of 10,000 cycles. Valve replacement again requires that the storage ring be let up to boil-off $\mathrm{N}_{2}$

By adding UHV valves on bean lines as seen in Figure 1, monochromators, mirfor boxes, and experimental chambers can be vacuum isolated without sealing the front end G-P gate valve. The front end UHV valve will be closed and sealed when working on the inside front end components or on the first VUV mirror box. The valve will also be closed and sealed to isolate a beam line when the ring must be brought up to boil-off $\mathrm{N}_{2}$. The front end valve will be closed but not sealed prior to closing isolating UHV valves on the beam line.

The front end UHV valve cannot be closed without also closing the photon mask to protect the valve from overheating. Located between the UHY valve and the storage ring, the photon mask is automatically closed whenever the UHV valve is closed. However, controls will be provided to close the mask independently of the UHV valve. Controls to close the front end valve and valve position displays are located at each experimental station. Opening the sealed UHV valve can only take place after beam line pressure and residual gas analysis have met NSLS standards. 
II.B Fast Valve

The NSLS fast valve closes in less than eight milliseconds and has a leak rate less than one Torr liter per second when closed. The valve aperture is $14 \times 140 \mathrm{~mm}$.

There are no manual controls for fast valves. They close automatically when the sensor pressure reaches a prescribed limit. Position indication will be provided from the fast valve actuator.

II.C Fast Valve Sensors

The NSLS has evaluated four types of cold discharge sensors:

a. Spark gap

5. Coaxial Discharge Switch

c. Penning Gauge (2 liters per sec ion pump)

d. Varian miniature appendage pump (see Appendix A)

The Varian miniature appendage pump has been selected as a standard sensor and its use will be mandatory on all front ends and beam lines. The design of the NSLS fast valve sensor will be found in Appendix A.

Sensors will be located to suit each type of beam line set-up or experimental condition. In general, one should be placed approximately five meters doinstream from the fast valve. Additional sensors and sensor circuits should be placed near potential breaks in the vacuum envelope. For the VUV experiment in Figure la, sensors should be located as follows:

a. Front mirror box

b. Monochromator-mirror box, (exit-slit housing)

For the $x$-ray experiment in Figure $1 b$, where the monochromator and mirror box are UHV-compatible, sensors should be placed as follows:

$a_{\text {. }}$ As far downstream, and if possible, more than five meters from the downstream end of the safety shutter.

b. Monochromator-mirror box

:. Adjacent to vacuum side of beryllium window.

A beryllium window will be used between the safety shutter and the monochromator when the monochromator and mirror box operate in helium. For this case, sensors will be installed in two places:

a. As far downstream ano, if possible, more than five meters from the downstream end of the safety shutter.

b. Adjacent to the vacuum side of the beryllium window. 


\section{VACUUM INTERLOCKS}

Fast valve sensors will protect the storage ring in the event of a beam line vacuum failure. There are sensors in the storage ring to protect beam lines from a storage ring vacuum failure.

If the pressure at any sensor is above $1 \times 10^{-5}$ Torr, the fast valve will be triggered. Triggering the fast valve simultaneously closes the photon mask and UHV valve. The safety interlock system will also dump the electron beam. If the pressure in the front end exceeds $7 \times 10^{-9}$ Torr because of a slow leak or power failure, the UHV valve in the front end will close and seal via a high pressure interlock with the ion gauge. The photon shutter will automatically close at this time. The fast valve will remain open.

Either the experimenter or the Safety Coordinator (beeper 824) can close, or close and seal, the front end UHV valve. Only an authorized NSLS staff member can open the closed and sealed valve after he is assured that the bean line pressure is $2 \times 10^{-9}$ Torr or less and a residual gas scan indicates acceptable gas composition with no offending hydrocarbons. Exceptions to these requirements must be authorized by $\mathrm{C}$. Foerster or $\mathrm{H}$. Halama. Under normal operating conditions the UHV valve will remain open. During injection it may be necessary for the Control Room operator to close the valve.

When venting part of a beam line to atmospheric pressure with boil-off $\mathrm{N}_{2}$ the fast valve sensors which serve the portion being vented must be bypassed. An interlock must prevent the sensors from being locked out when the entire beam line is once again under vacuum.

In order not to seal the front end UHV valve more than necessary, UHV valves will be used whenever possible on beam lines to isolate monochromators and mirror boxes. Before closing the isolating valves, the experimenter will close the front end mask. Isolation valves should not be opened unless the pressure in this section is under hard. vacuum, the pressure in the front end is $2 \times 10^{-9}$ Torr, and the residual gas specification is met. Vacuum gauges will be installed in each vacuum separable portion of a beam line. Should an isolation valve be opened accidentally, the G-P valve will protect the storage ring and the fast valve will be actuated. The "bleeding-up" and "returning to operation" procedures for each beam line in the "NSLS Beam Line Vacuum Procedures" book should be followed. Copies are posted at each beam line.

For some windowless experiments where a particularly noxious sample or environment is used, the NSLS Design Review Committee may require additional fast and UHV valves and triggers on the beam line. If the valves are placed at a point where the photon beam is focused, small diameter commercia? valves can be used. 
IV. GUIDELINES FOR UHV VACUUM SYSTEMS

The standards cited below are used for all NSLS beam line hardware tht is not separated from the storage ring vacuum system by a window. It is the NSLS policy that all front ends must operate at or below $2 \times 10^{-9}$ Torr and be hydrocarbon-free. (See Section 6, Acceptance Tests). Users may deviate from the standards that follow as long as the performance requirements are met. However, we strongly recommend that these guidelines be followed to ensure that NSLS UHV criteria are met, that optical surfaces will have reasonably long lifetimes without contamination, and that there will be interchangeability with NSLS vacuum hardware.

IV.A Materials

IV.1.1. The following materials are UHV-compatible:

Stainless Steel - Austenitic, 300 Series

Preferred types are $304 \mathrm{~L}, 316 \mathrm{~L}, 321$ and 347. The "L" signifies low carbon content which reduces carbide precipitation in the heat affected weld areas. Carbide precipitation can lead to corrosion and reduced strength.

Aluminum - 6061-T6 is a high-strength, easily weldable alloy. If the material is to be bent, use 5454, 5058, etc. for crack-free bends but at a somewhat reduced strength.

Copper - Oxygen-free high conductivity, OFHC

Titanium - Commercially pure, dircraft quality, type 50A

Ceramics, Refractories

Alumina and similar oxide ceramics

Sapphire

Glass

Metals, Inorganic Materials

Noble metals

Inconel, Mone 1

Kovar

Beryllium Copper

Mu Metal

Lithium Fluoride

Magnesium Fluoride

Aluminum-to-stainless transition material, as noted in Section IVA.2.

IV.A.2 Aluminum-to-Stainless Steel Transition Material

The following transition materials have been successfully used on UHV systems. However, before they can be used with confidence; numerous inspections, bakeout cycles and leak tests must be made before and after fabrication. Since these materials can vary from lot to lot, all pieces should be $100 \%$ inspected and tested. 
It is desirable to make tests for porosity and inclusions by means of radiography, ultrasonics and vacuum leak testing, depending upon the geometry of the transition material. However, thermal cycling the material is a must. Sources of supply are listed below:

Roll-Bonded Plate and Shells:

- Clad Metals, Inc., Cannonsburg, $\mathrm{Pa}$. 15317

Roll-Bonded Plate

- Kaiser Aluminum and Chemical Sales 300 Lakeside Dr. Oakland, California 94612

Friction-Welded Bars

- Coatings, Inc. 6623 West Mitchell Si., Milwaukee, WI 53214

Explosion-Bonded Plate

- Aerospace Materials, Inc. 249 Fornof Road, Columbus, $\mathrm{OH} 43207$

- Explosive Fabricators, Inc. Louisville, co 80027

- E.I. duPont de Nemours and Co. Wilmington, DE 19898

IV.A.3 The following materials are not UHV compatible:

Zinc - Bearing metals and alloys

Cadmium - Bearing metals and alloys

Elastomers - 0-ring-sealed flanges and valves Organics - 0il-bearing pumps

IV.B Vacuum Hardware

IV.B.1 Pumps

The following types of pumps are hydrocarbon-free and are the only pumps permitted upstream of the first monochromator apertures:

- Sputter-ion pumps

- Titanium sublimatin pumps

- NEG pumps

The following types of pumps may be used for rough pumping the beam line or during bake out. They must be interlock protected through an interconnecting valve in case of pressure failure.

- Turbopumps

- Cryopumps

- Sorption pumps 


\section{IV.B.2 Valves}

Commercial, al1-meta1, bakeable UHV valves available in various styles and sizes from a number of manufacturers have been found to be acceptable. The NSLS Vacuum Group can advise beam lines concerning valves. Valve flanges must be in accordance with Sec. IV.B. 3 below.

\section{IV.B.3 Flanges}

The "Conflat" type flange is standard on NSLS beam lines. Varian, the inventor of this flange, has licensed a number of manufacturers to produce them. The flange must be machined from cross-forged blanks or from vacuum remelted bar stock. This flange is described in Specification SLS-07.14-1-1 in Appendix B.

The copper sealing gaskets and the high strength clamping bolts are described in NSLS specificarions SLS-07.14-4-1 and SLS-07.14-5-1, respectively.

IV.C Acoustic Delay Lines and Beam Line Fast Valves

It was stated above that the storage ring is protected from an accidental inrush of air from a break in beam line vacuum. This is done through the front end fast valve which is activated by the coincident action of two triggers. Such protection is possible only if there is enough time for the fast valve to close before the arrival of the wave front. It was recently reported that the velocity of a pressure front in a vacuum beam tube in the range of $10^{-6}$ to $10^{-3}$ millibars is about one meter per millisecond for air and twice that for helium. With a fast valve now under consideration, it will require 5 to 7 meters between the trigger and the fast valve to intercept the wave front. Since this space is not always available, especially for VUV experiments, it is highly recommended that an acoustic delay line similar to that shown in Appendix B, be used. It should be located as close as practicable to a potential break in the vacuum envelope.

Where space restrictions prohibit the use of an acoustic delay line, it has been shown ${ }^{2}$ that the combination of a small aperture in a monochromator exit slit and a conical disc with a small hole that is located 25 to $30 \mathrm{~cm}$ upstream of the exit slit (with respect to the shock wave), can substantially delay the shock wave. See Appendix B.

\section{IV.D Instrumentation}

Gauges - The following gauges are used at the NSLS and are recommended for use on beam line vacuum systems. Each gauge is described in the NSLS specifications listed below:

\footnotetext{
Measurements on the Efficiency of Acoustic Delay Lines in View of Beamlines for Synchrotron Radiation, H, Betz, P. Hofbauer, and A. Henberger, J. Vac. Sci. Tech Note, 16 (3) May/June 1979.

${ }^{2}$ Measurement of Shock Wave Flight Times in Long Pipes, W. Peatman and

E.W. Weiner, BESSY, Technischen Bericht 18/79, November 1979.
} 


SLS-07.13-4-1 Hot Filament Ionization Gauge, for
SLS-07.13-3-1 $\begin{aligned} & \text { pressures } 10^{-4} \text { to } 10^{-11} \text { Torr. } \\ & \begin{array}{l}\text { Pressures } 10^{-3} \text { to } 10^{-1} \text { Torr. Must be } \\ \text { modified for UHV (remove "0" ring and } \\ \text { weld). }\end{array} \\ & \text { SLS-07.13-1-1 }\end{aligned}$

IV.E Fabrication and Testing

IV.E.1 Machining

a. The use of sulphur-bearing oils and abrasives is prohibited. Use CIMCOOL, KOOLMIST No. 77, MOBIL CUT MAX, or MISSLE LUB No. 5.

b. All blind holes to be vented.

c. Avoid high impedance connections between parts.

IV.E.2 Welding

a. No vacuum-to-water joints.

b. Weld to be on vacuum side of joint if possible. If not, full penetration welds to be used to eliminate virtual leaks.

c. Where high strength requires welding on both sides of thick sections, the side facing the vacuum is to be continuous and the opposide side intermittent. At no time should there be continuous welds on both sides of joint.

d. Tungsten Inert Gas (TIG) and Electron Beam welding are recommended for UHV vacuum applications.

e. Hydrogen brazed joints are acceptable.

f. Silver soldered and soft soldered joints are not acceptable.

IV.E.3 Leak Test

The total leak rate of individual parts and assemblies must not exceed $2 \times 10^{-10}$ std $\mathrm{cc} / \mathrm{sec} \mathrm{He}$. A $250^{\circ} \mathrm{C}$ vacuum bakeout prior to leak checking is recommended to drive out any cleaning solutions or machining fluids that might otherwise plug a leak. It is recommended that all parts be chemically cleaned or vacuum baked prior to assembly on the NSLS.* After cleaniris, the vacuum surfaces should not be touched with bare hancis. (The outgassing rate of a fingerprint is reported to be $10^{-5}$ Torr $1 i \operatorname{ter} / \mathrm{sec} \mathrm{cm}^{2}$ ).

ॠSee Section IV.F, NSLS Cleaning Facility. 
IV.E.4 References

The following references are included for more comprehensive data:

Design Subject
General Vacuum Technology
Conductances
Differential Pumping
Outgassing
Materiais
Welding Design

References

all

$1,7,12,21$

19,20

$2,3,7,12,21$

$4,9,16$

9,21

IV.F NSLS Cleaning Facility

A NSLS cleaning facility has been established to acid clean UHV components and hardware. This facility was set up primarily to clean aluminum and stainless steel. However, small copper and ceramic pieces can also be processed.

Experimental beam line components for Participating Research Teams and General Users may be processed through this facility after receiving necessary accounting and scheduling approval.

\section{Cleaning Procedure}

A caustic etch is used for aluminum parts and hydrofluoric/nitric acid solution for stainless steel. See NSLS Specification SLS-07.12-1-1 in Appendix B, for details.

Tank Size

34 " wide, $48^{\prime \prime}$ long, $30^{\prime \prime}$ deep

There is a one ton crane over the tanks. 


\section{DESIGN REVIEW}

Experimenters are required to submit plans of their equipment to the NSLS for a review of the vacuum design. Included shall be:

- Beam line assembly drawings to scale

- A list of materials of construction

- Gas burden expected from target samples

It is expected that experimenters will adhere to NSLS guidelines and standards for material and component selections, cleaning, and fabrication. Where guidelines and standards are not followed, user shall demonstrate how his design will not compromise the vacuum requirements of the storage ring.

It is recommended that the design review shall take place before beam line fabrication begins or major vacuum components urdered. NSLS approval of a PRT design does not relieve the PRT from satisfying the requirements as stated in the acceptance test below. 
Before a beam line is connected to ring vacuum for the first time (Ref: SLS 07-19-12-1, Procedure to Open Front End Valve), the following tests will be made:

a. Pressure: The system will maintain a base pressure of no more than $2 \times 10^{-9}$ Torr as measured at the front end ionization gauge.

b. A residual gas analysis: The predominant gas component should be hydrogen and be at least $60 \%$ of the total pressure. There should be no evidence of air or other leaks in the system and masses greater than 28 amu shall be less than $10 \%$ of the total pressure. The sum of components at mass locations 39,41,43,45 and greater shall total less than $1 \times 10^{-11}\left(N_{2}\right.$ equivalent $)$.

Thereafter, eack time a beam line is opened to ring vacuum, steps a and $b$ above must be satisfactorily completed if the front end G-P valve has been closed and sealed.

The following vacuum interlocks on users' apparatus will be satisfactorily demonstrated prior to the initial start up of an experiment:

- Fast valve sensors

- Rising pressure from slow leak to close UHV valve

- High system pressure in beam line prevents opening of UHY valve in front end

- Auxiliary fast valves on beam lines, where required.

When a part of an existing beam line is brought up to air or conditions are otherwise changed that would affect the vacuum, the beam line can be returned to service only when steps $a$ and $b$ of Section VI.A are sat isfactorily completed. See NSLS Beam Line Vacuum Procedures Book.

It will be the responsibility of the experimenter to demonstrate, in collaboration with NSLS staff, that adequate means have been provided to impede a pressure wave front from an accidental break in his vacuum system so that it can be effectively stopped by the fast valve. For purposes of design, use a fast valve closing time of 7 milliseconds. 


\section{REFERENCES}

1. A. Guthrie and R.K. Wakerling, Vacuum Equipment and Techniques, McGraw Hill, 1949.

2. P.A. Redhead, J.P. Hobson, and E.V. Kornelson, The Physical Basis of U1trahigh Vacuum, Chapman and Hall, 1968.

3. A.E. Barrington, High Vacuum Engineering, Prentice-Ha11, 1964.

4. A.H. Beck (Ed.) Handbook of Vacuum Physics, Pergamon, 1965-1968.

5. W.F. Brunner and T.H. Batzer, Practical Vacuum Techniques, Krieger, 1974.

6. L.G. Carpenter, Vacuum Technology - An Introduction, Elsevier, 1970.

7. S. Dushman, Scientific Foundations of Vacuum Techirique, 2nd Edition, (J.M. Lafferty, Ed.), Wiley, 1962.

8. N.W. Robinson, Physical Principles of Ultrahigh Vacuum Systems and Equipment, Chapman and Hall, 1968.

9. F. Rosebury, Handbook of Electron Tube and Vacuum Techniques, Addison-Wes ley, 1965.

10. A. Roth, Vacuum Sealing Techniques, Pergamon, 1966.

11. H.A. Steinherz, Handbook of High Vacuum Engineering, Reinhold, 1963.

12. C.M. Yan Atta, Vacuum Science and Engineering, McGraw-Hi11, 1965.

13. J. Yarwood, High Vacuum Technique, 4th edition, Chapman and Mal1, 1967.

14. J. Yarwood, et al., Vacuum Manual, Halsted Press, 1973.

15. K. Diels and R. Jaekel, Leybold Vacuum Handbook, (H. Adam and J. Edwards, trans.), Pergamon, 1966).

16. W. Espe, Materials of High Vacuum Technology, 3 Vols., Pergamon, 1968.

17. A. Guthrie, Vacuum Technology, Wiley, 1963.

18. J.H. Leck, Pressure Measurement in Vacuum Systems, Chapman and Ha1l, 1964.

19. J.A.R. Samson, Techniques of Ultraviolet Spectroscopy, John Wiley and Sons, 1967, pg. $\overline{92 .}$

20. R.C. Knechtli, Distributed Differential Pumping

21. A. Roth, Vacuum Technology, North-Holland, 1976. 
APPENDIX A

Acoustic Delay Line

Experiments and calculations ${ }^{1-4}$ show that the efficiency of an acoustic delay line is dependent upon such factors as:

1. Overall length, (L)

2. Ratio of diameter of chamber to aperture, $D / d$

3. Distance between segments

4. Number of segments

5. Shape of segments

Each delay line must be designed to suit its particular application. The aperture of each segment must clear the diverging photon beam. Ideally, the delay line would be located near the source of the vacuum leak and at a point where the beam was focused. The ratio of the diarreter of the chamber to the equiyalent diameter of the aperture affects the efficiency. Jean and Rauss found a $D / d$ of 10 to be four times as efficient as a $0 / d$ of 5 . Betz, et al. 3 reported that conical segments doubled the efficiency of f1at segments for an acoustic delay line with a $D / d=5$.

Betz, et al., also demonstrated that the efficiency improved sharply with increasing distance between segments up to 10 or $15 \mathrm{~cm}$, and reached a maximum at $30 \mathrm{~cm}$. The most effective total length of the delay line is said to be 4 to 5 times the segment distance.

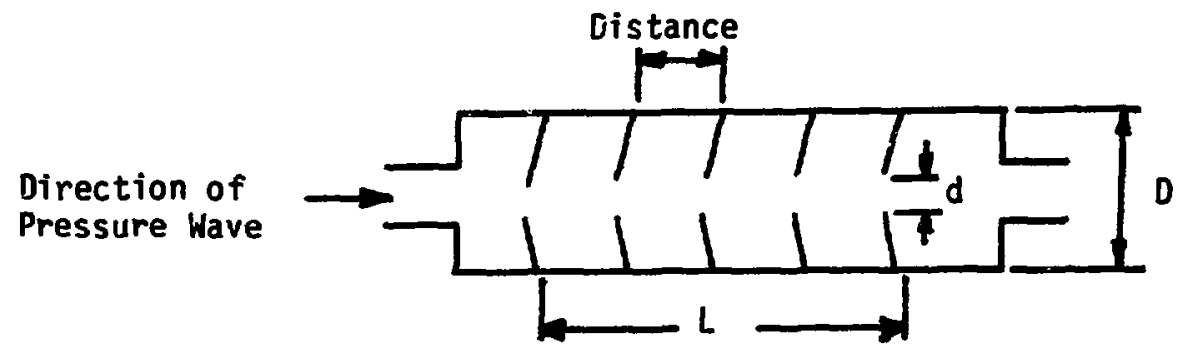

Peatman and Weiner ${ }^{4}$, using the apparatus shown below, showed that considerable delay times could be achieved using a limited number of baffles in conjunction with the exit slit of a monochromator.

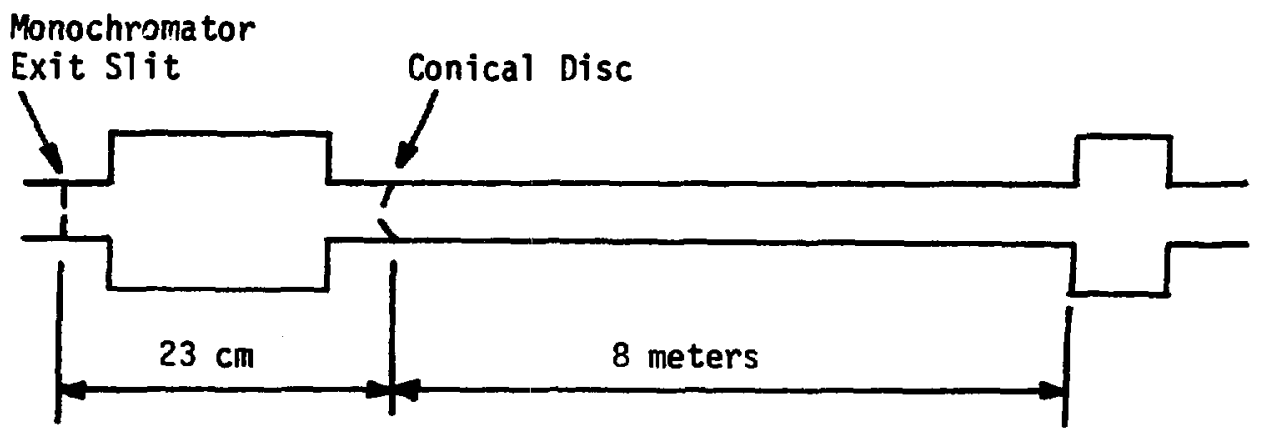


The data associated with their experiments are noted below:

\begin{tabular}{|c|c|c|c|}
\hline Exit slit (m) & Aperture (mm) & $\begin{array}{l}\text { Time to Raise Pressure } \\
\text { at Fast Valve to } \\
3 \times 10 \text { Torr milliseconds } \\
\end{array}$ & $\begin{array}{c}\text { Average } \\
\text { Yelocity }(\mathrm{m} / \mathrm{msec})\end{array}$ \\
\hline \multirow[t]{2}{*}{$0.2 \times 6$} & 15 & 87 & 0.1 \\
\hline & $8 \times 9$ & 140 & 0.06 \\
\hline $0.25 \times 8$ & 15 & 72 & 0.12 \\
\hline \multirow[t]{2}{*}{$8 \times 9$} & 15 & 24 & 0.35 \\
\hline & $8 \times 9$ & 34 & 0.25 \\
\hline 60 & none & 8.4 & 1.0 \\
\hline
\end{tabular}

A summary of Peatman and Weiner's conclusions:

a. The velocity of the shock wave can be reduced by a factor of at least 3 , depending upon the size of the exit slit and aperture.

b. Flight time is unaffected for initial pressures of less than $3 \times 10^{-5}$ Torr.

c. Spacing between slit and conical disc of $25-30 \mathrm{~cm}$ is optimal.

d. Nonlinear geometries such as monochromators, mirror boxes, etc. and the volume of the system do not add to the delay time.

e. Slit size is the most important factor in delay time.

f. Adding the conical disc improved the delay time between 40 and $70 \%$.

The designer should take into acount the considerable surface area in the acoustic delay line. Outgassing from this surface could adversely affect system pressure unless a vacuum pump is added. Becalise of the high impedance of an acoustic delay it can be used with vacuum pumps to provide differential pumping for certain classes of experiments.

1. Design of a Synchrotron Radition for Orsay's ACO Storage Ring: Lure, P.M. Guyon, C. Departex and G. Morel (undated).

2. Protection Against Re-entry of Air into Vacuum Installations, R. Jean and J. Rauss, LeVide, No. 111, May-June, 1964, pp. 123-127, SLAC Translation-159.

3. Measurements in the Efficiency of Acoustic Delay Lines in View of Beam Lines for Synchrotron Radiation, H. Betz, P. Hofbauer, A. Heuberger, J. Vac. Sci. Tech Note 16 (3) May/June 1979.

4. Measurements of Shock Wave Flight Times in Long Pipes, W. Peatman, and E.W. Weiner, BESSY, Technischer Bericht 18/79, November 1979. 
NATIONAL SYNCHROTRON LIGHT SOURCE

TECRNICAL SPECIFICATION

for

TENTATIVE STANDARDS OF THE AMERICAN VACUUM SOCIETY

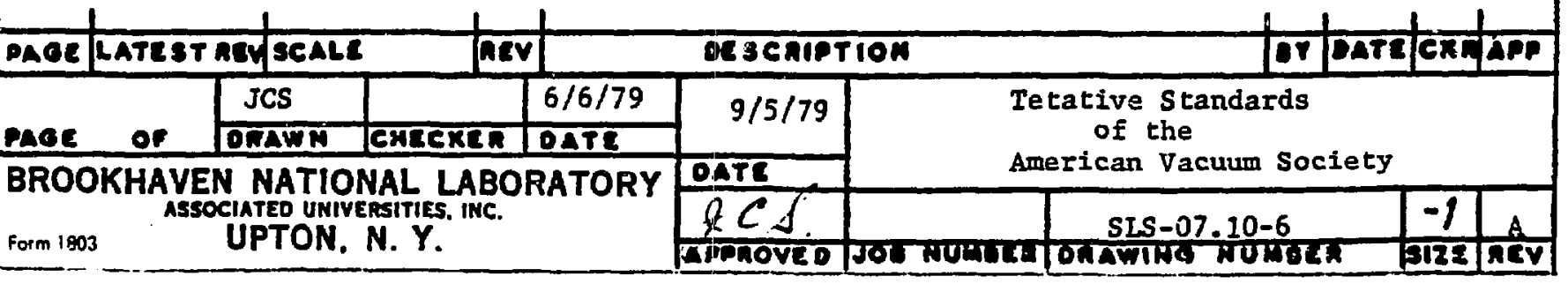


2.1 Calibration of Leak Detectors of the Mass Spectrometer Type.

2.2 Method for Vacuum Leak Calibration.

2.3 Procedure for Calibrating Gas Analyzers of the Mass Spectrometer Type.

3.1 Unbaked, Ungrooved Bol ted Vacuum Connection Flanges, Nominal Sizes $4 \mathrm{in}$. to $24 \mathrm{in}$.

3.2 Flanges Bakeable to $500^{\circ} \mathrm{C}$.

3.3 Method for Testing Flange Seals to $5000 \mathrm{C}$.

3.4 Dimensions for Unbaked Flanges, Light Series.

3.6 Procedure for Rating All-Metal Valves 8akeable to above $2500 \mathrm{C}$.

4.1 Procedure for Measuring Speed of Oil Diffusion Pumps.

4.2 Procedure for Measuring Throughput of $0 \mathrm{il}$ Diffusion Pumps.

43 Procedure for Measuring the Forepressure Characteristics of 0 il Diffusion Pumps.

4.4 Procedure for Measuring the Ultimate Pressure of $0 i l$ Diffusion Pumps.

4.5 Procedure for Measuring Backstreaming of 0 il Diffusion Pumps

\$.6 Procedure for ireasuring the Warmup and Cooldown Characteristics of Oil Diffusion Pumps.

4.7 Procedure for Measuring the Ultimate Pressure of Pumps wi thout Working Fluids.

4.8 Procedure for Measuring Speed of Pumps without Working Fluids.

4. 10 Determining the Refrigerant Consumption and Temperature Characteristics of Baffles and Traps.

5.1 Measurement of 8 lank-off Pressure (Permanent Gases) of Positive Displacement Mechanical Vacuum Pumps.

5.2 Presentation of Pumping Speed Curves of Mechanical Pumps.

5.3 Method for Measuring Pumping Speed of Mechanical Vacuum Pumps for Permanent Gases.

6.2 Procedure for Calibrating Vacuum Gauges of the Thermal Conductivity Type.

6.4 Procedure for Calibrating Hot Filament lonization Gauges Against a Reference Manometer in the Range 10-2-10-5 Torr.

6.5 Procedures for the Calibration of Hot Filament Ionization Gauge Controls.

7.1 Graphic Symbols in Vacuum Technology.

9.1 Reporting of Outgassing Data.

9.2 Reporting of Thermal Degassing Data. 
NATIONAL SYNCHROTRON IIGET SOURCE

TECHNICAL SPECIFICATIONS

FOR

CLEANING VACUUM" COMPONENTS AND HARDTARE

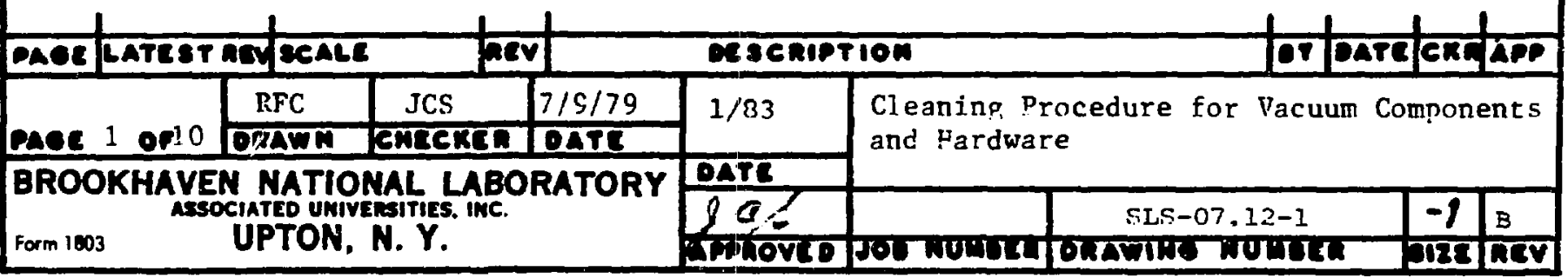


TABLE OF CONTENTS

Start-up Procedure

Page

Aluminum, Caustic Etch Procedure A1loys 6061, 6063

Stalnless Steel 300 Serles, Plckling

Alumfnum - Stalnless Transistor Material

Stalaless Steel, Heavy Scale

A Word About Glas-Shot

Titanim - Procedure Used for LIght Scale

Ceramte Cleaninga:

A. Ceramfc-to-Metal Feedthroughs

B. Ceramic Parts

Copper Cleaning:

A. Heavily Oxidized Copper

B. OFHC Copper

C. OFHC Copper - Bright DIp

\begin{tabular}{|c|c|c|c|c|c|c|c|c|c|}
\hline 2 of 10 & $\frac{\operatorname{RFC}}{\text { ORAWN }}$ & $\begin{array}{l}\text { JCS } \\
\text { CHECKRR }\end{array}$ & $\frac{7 / 9 / 79}{\text { DATE }}$ & $1 / 83$ & \multirow{2}{*}{\multicolumn{2}{|c|}{$\begin{array}{l}\text { Cleaning Procedures for } \\
\text { and Hardware }\end{array}$}} & \multirow[t]{2}{*}{ Vacuum } & \multirow{2}{*}{\multicolumn{2}{|c|}{ Components }} \\
\hline \multirow{2}{*}{\multicolumn{4}{|c|}{$\begin{array}{l}\text { BROOKHAVEN NATIONAL LABORATORY } \\
\text { AssochATED UNIVEAsITIEs. IMC. } \\
\text { UPTON, N. Y. }\end{array}$}} & DATE & & & & & \\
\hline & & & & $\frac{9 C .}{\text { armoveo }}$ & Jou NoSULA & 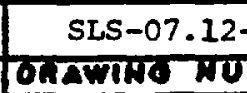 & -1 & \begin{tabular}{|c|}
-1 \\
122
\end{tabular} & $\frac{B}{R E V}$ \\
\hline
\end{tabular}


1. Swltch on degreaser. Light will come on. Make sure cooling water is flowing to untt.

2. Switch on oven.

3. Check that all tank heaters are on. Press "reset" if necessary. (Heaters are only shut off over weekends and/or holldays.)

4. Turn on delonized water pump and open valve all the way. When steady flow -: outlet is achleved close valve so that stop is in vertical position. $\therefore-$ zch on Indlcator 1ights. (Clean screen on water conditioner tank once a iesi.)

5. Tura on aerating compressor.

6. Plug in filter pump. Check gauge pressure, if 5 psi or greacer, replace filters. Clean inlet screen daily.

7. Srart-up "scrubber" by doing the following:

1. Close bypass valve.

2. Open valves $\mathbf{V} 1$ and $\mathbf{2}$.

3. Suitch on pump.

Fill tank with water to just below the overflow level while "scrubber" is operating. Check perfodically durfing the day as evaporation (especially in warm weather) from system will occur. Level should not be allowed to fall below the halfway polnt.

8. Check that sump pumps are operating. If water is overflowing from sump reservolr a problem exists.

9. When tanks that are heated are up to temperature then remove covers. Open valves at water ringe tanks to give a small flow.

10. Open afr valves at tanks.

11. Turn on $\mathrm{pH}$ controllers for "scrubber" and water rinse tanks.

12. Reverse procedure to shut down.

\begin{tabular}{|c|c|c|c|c|c|c|c|c|c|c|c|}
\hline Puge & LATEST & RIy seAL & $\sqrt{n e}$ & & DLSCAIP1 & $10 \mathrm{n}$ & & $D T$ & DATE & Bera & APP \\
\hline pace & 3 of 10 & $\frac{\text { RFC }}{\text { ORAWN }}$ & $\frac{\text { JCS }}{\text { CMECRER }}$ & $\frac{7 / 9 / 79}{\text { DATE }}$ & $1 / 83$ & \multirow{2}{*}{\multicolumn{6}{|c|}{$\begin{array}{l}\text { Cleaning Procedures for Vacuum } \\
\text { Components and Hardware }\end{array}$}} \\
\hline \multirow{3}{*}{\multicolumn{5}{|c|}{ 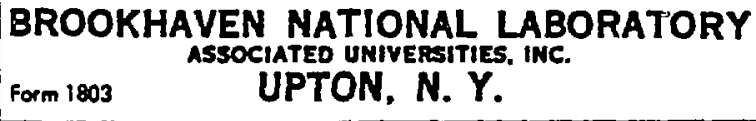 }} & Dare & & & & & & \\
\hline & & & & & $9 C$ & & SLS-07.12- & & & -1 & B \\
\hline & & & & & Apiphove & Jot RULULA & DTAWTIS NUT & WIL & & II2: & AEV \\
\hline
\end{tabular}


Alum1num, Caust1c Etch Procedure, Alloys 6061, 6063

1. Vapor degrease in hot trichlorethane vapor for 5 minutes.

2. Soak in non-etch alkaline cleaner, Oakite 166 , for 5 minutes at $130^{\circ} \mathrm{F}$ to $150^{\circ} \mathrm{F}$, with air agitation.

3. Rinse in cold running tap water for 2 minutes, if water break appears repeat step 2 .

4. Etch In 67 Oakite 360L solution for 5 minutes at $100^{\circ} \mathrm{F}$ to $110^{\circ} \mathrm{F}$, wlth alr agitation.

5. Rinse in cold running tap water for 2 minutes.

6. Desmutt at room temperature in Wyandotte Alutone for 5 minutes, with air agitation. Use same solution as in step $\$ 5$.

7. Rinse in cold running tap water for 2 minutes.

8. Rinse in hot, $160^{\circ} \mathrm{F}$, delonized water for 2 minutes, with alr agitation (minimum resistivity 5,000,000 ohms).

9. a. Electrontc grade methanol rinse (if desired).

b. Bake in oven at $250^{\circ} \mathrm{F}$.

10. Close all ports, or wrap entire part: ist - lint-free paper

$$
\text { 2nd - new aluminum foll }
$$

\section{Alternate Solutions}

Step 4. Etch in $20 \% \mathrm{~N}_{\mathrm{a}} \mathrm{OH}$ by volume for 5 minutes at $100^{\circ} \mathrm{F}$ to $110^{\circ} \mathrm{I}$.

Step 6. Desmutt in room temperature solution of $30 \mathrm{z} \mathrm{ENO}_{3}$ by volume for 5 minutes.

\begin{tabular}{|c|c|c|c|c|c|c|c|c|c|c|}
\hline DAGE LATEST & Aty scate & ne & & \multicolumn{2}{|c|}{ Drseniption } & & DT 10 & ATEF & CXE & Ape \\
\hline pace 4 or 10 & $\frac{\text { RFC }}{\text { DRAWN }}$ & JCS & 7/9/79 & $1 . / 83$ & \multirow{2}{*}{\multicolumn{2}{|c|}{$\begin{array}{l}\text { Fleaning Procedures for } \\
\text { and Hardware }\end{array}$}} & Vacuum & \multicolumn{3}{|c|}{ Components } \\
\hline \multirow{2}{*}{\multicolumn{4}{|c|}{$\begin{array}{l}\text { BROOKHAVEN NATIONAL LABORATORY } \\
\text { ASSOCIATED UNIVERSITIES, INC. } \\
\text { UPTON } 1803 \quad \text { UPTON, N. Y. }\end{array}$}} & DATE & & & & & & \\
\hline & & & & $\frac{9<1}{\text { inpoven }}$ & Jor & $\frac{\text { SLS-07.1 }}{\text { or. }}$ & $\frac{2-1}{\text { UTाER }}$ & & -1 & $\frac{B}{R E Y}$ \\
\hline
\end{tabular}


Stainless Steel 300 Serles, Plckling

1. Vapor degrease in hot trichloroethane vapor for 5 minutes.

2. Soak in non-etch alkaline cleaner, Oaklte 166, for 5 minutes at $130^{\circ} \mathrm{F}$ to $150^{\circ} \mathrm{F}$, with alr agitation.

3. Rinse In cold running tap water for 2 minutes. If water break appears repeat step 2 .

4. PIckle in Hydrofluoric-Nitric acid solution, at room temperature ( $70^{\circ} \mathrm{F}$ ) for 5 to 10 minutes, with alr agltation.

$$
\begin{array}{ll}
\text { Eydrofluoric actd } & -337 \text { by volume } \\
\text { Nitric acid, } 42^{\circ} \text { Baume } & -337 \text { by volume } \\
\text { Distilled water } & -337 \text { by volume }
\end{array}
$$

Imersion time shall be sufficlent to clean surface of scale and oxide. Care should be taken to avold overetching. Parts may be brushed with a stalnless steel brush to faclittate oxfde removal.

5. Rinse in cold running tap water for 2 minutes.

a. Desmut in alutone for 2 minutes, followed by $\mathrm{H}_{2} \mathrm{O}$ rinse (2 minutes).

6. Rinse in hot, $160^{\circ} \mathrm{F}$, delonized water for 2 minutes, with afr agltation. (Minimum resistivity 500,000 ohms.)

7. a. Electronic grade methanol rinse (1f desired).

b. Bake In oven at $250^{\circ} \mathrm{Z}$.

8. Close all ports, or wrap entlre part: 1st - lint-free paper

2nd - new aluminim foll

Stalnless Steel, Heavy Scale

For stainless steel parts that have heavy scale from Vacuum Deposition or Materlal Fabrication the following procedure should be used:

1. Vapor degrease in trichloroethane vapor for 5 minutes.

2. Blast wth "Glass-Shot" Bead Blaster, unt1l scaled surface is removed.

3. Proceed with procedure used for stalnless steel, 300 serles, plckling.

Aluminum - Stainless Steel Transition Material

Clean In caustic etch solutions as aluminum part. Ref. page?.

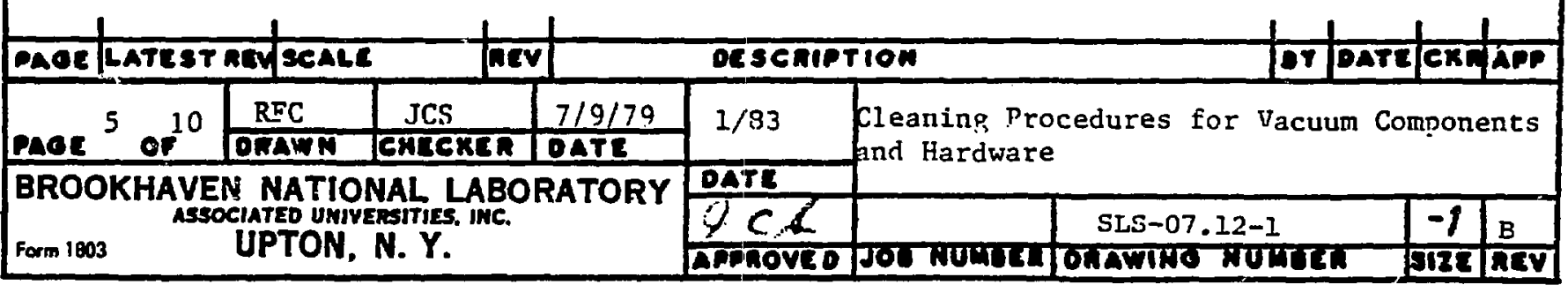




\section{A Word About Glas-shot}

Glas-shot is an abrasive for surface treatment of metals by particulate bombardment for it? purposes of cold working, cleaning, honing, polishing, peening, or finlshing. Unlike other abrasives, Glas-shot removes no base metal, leaves no Imbedment, w1Il produce a matte finlsh. The effects of Glas-shot can be classed as mechanlcal surface reformations. Natlonal Synchrotron Light Source w11 be using Glas-shot as a treatment for parts that are heavily scaled from vacuum deposition or materlal fabrication.

Glas-shot beads are manufactured of high grade, optlcal crown glass, soda lime type. High in solica content, they contain no lead and are resistant to atmospherlc wolsture, dilute aclds and alkalles. Annealed in the spherfcal shape for stress equalization, they resist wear and fracture...exhibit high resilience and restitution. A minfmum of 907 are true spheres and those with sharp or angular ejges will not exceed 17. Glas-shot are crystal clear and free from deleterlous surface films. No more than 27 show milkiness, scores or scratches. Bead slzes range from $0.0005^{\prime \prime}$, (Ms-XI) to $0.0276^{\prime \prime}$ (MS-XPX).

\section{Titanium - Procedure used for light scale}

1. Vapor degrease in hot trichloroethane vapor for 5 minutes.

2. Soak in non-etch alkaline cleaner, Oak1te 166 , for 5 minutes at $130^{\circ} \mathrm{F}$ to $150^{\circ} \mathrm{F}$, with alr agitation.

3. Rinse in cold running tap water for 2 minutes. If water break appears repeat step 2 .

4. Pickle in Hydrofluoric-Nitric acid solution, at room temperature ( $70^{\circ} \mathrm{F}$ ) for 15-30 seconds with alr agltation.

$$
\begin{array}{ll}
487 \mathrm{HF} & -337 \text { by volume } \\
42 & \text { Baume } \mathrm{HNO}_{3}-33 \% \text { by volume } \\
\text { Delonized } \mathrm{H}_{2} \mathrm{O} & -33 \% \text { by volume }
\end{array}
$$

The above solution is used for 1ight scale. The nitric acid content must not be allowed to drop, in order to avold hydrogen embrittlement.

5. Rinse in cold running tap water for 2 minutes. Wpe with sponge.

6. Rinse in hot, $160^{\circ} \mathrm{F}$, delonlzed water for 2 minutes, with afr agltation. (Minimum resistivity 500,000 ohms.)

7. a. Electronle grade methanol rinse (If and when avallable).

b. Bake In oven at $250^{\circ} \mathrm{F}$.

8. Close all ports, or wrap ent1re part: lst - I1nt free paper

$$
\text { 2nd - new aluminum foll }
$$

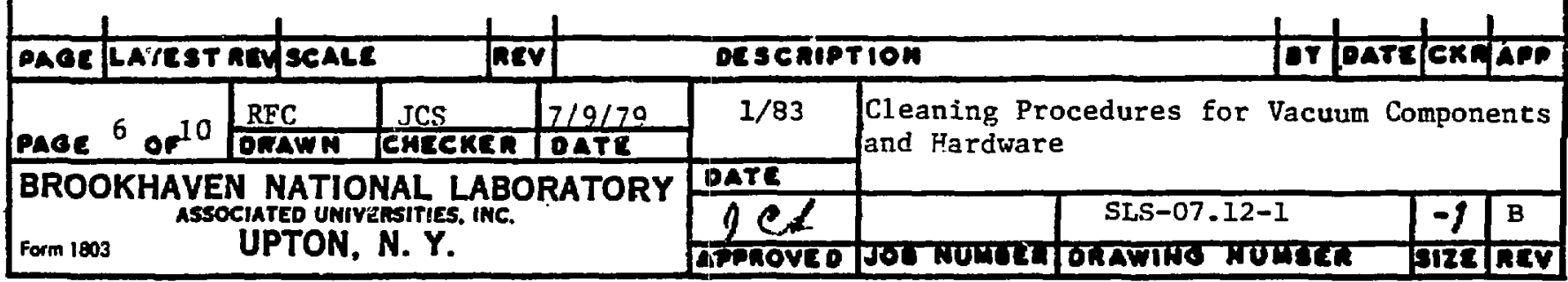


Titanium, Heavy Scale

For titanium parts that have tough millscale, the following procedure should be used:

1. Vapor degrease in trichloroethane vapor for 5 minutes.

2. Blast with "Glas-shot" bead blaster, unt1l scale is removed.

3. Proceed with procedure used for titanium, light scale.

Ceramic Cleaning

A. Ceramic-to-Metal Feedthroughs

The cracks and crevices usually present in ceramlc-to-metal feedthroughs present particular cleaning problems, in that there is a possibility of trapping the acid cleaning solution being used. Therefore, the standard cleaning procedure used to clean the Feedthroughs is as follows:

1. Vapor degrease in hot trichloroethane for 15 minutes. Place the Feedthrough on side in a stalnless steel basket.

2. Oven dry at $150^{\circ} \mathrm{F}$ for approximately 2 hours.

B. Ceramic parts used in the vacuum system as insulators, spacers, etc. must be chemically sleaned as follows:

1. Vapor degrease in hot trichloroethane vapor for 5 minutes.

2. Soak in non-etch alkaline cleaner, Oakite 166, for 5 minutes at $130^{\circ} \mathrm{F}$ to $150^{\circ} \mathrm{F}$, with air agitation.

3. Rinse in cold running tap water for 2 minutes, if water break appears repeat 8 tep 2 .

4. Soak in $150^{\circ} \mathrm{F}$ delonized water for 1 hour (minimum resistivity 500,000 ohms .)

5. Bake in oven at $250^{\circ} \mathrm{F}$.

6. Close all ports, or wrap entire part: lst - lint free paper

2nd - new aluminum foll

C. Removal of Coatings on Ceramic Chambers

1. Vapor degrease for 5 minutes.

2. Soak in non-etch cleaner for 5 minutes.

3. Rinse in water for 2 minutes.

4. Soak in $\mathrm{HF}-\mathrm{HNO}_{3}$ solution for 1 minute.

5. Rinse in water for at least 4 hours.

6. Brush off coating wth stainless steel brush. Follow with delonized water for two minutes.

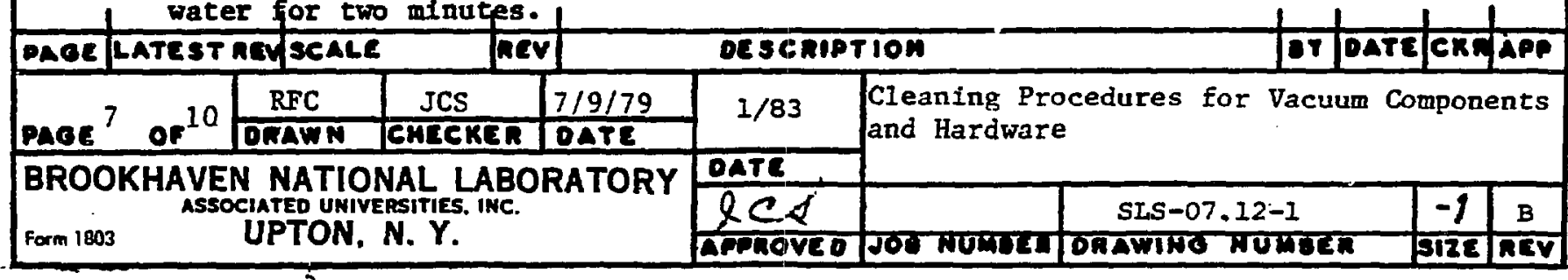




\section{Copper Cleaning}

A. Heavily Oxidized Copper

On copper and copper alloys contalning more than $85 \%$ copper, oxide films will contain a high percentage of cuprous oxide (CU20) which is not easily removed by sulfuric acid plciles, and the addition of an oxidizing agent is desirable. Therefore, in cases such as described the following procedure w111 be used:

1. Vapor degrease in hot trichloroethane vapor for 5 minutes.

2. Soak In non-etch alkaline cleaner, Oak1te 166 , for 5 minutes at $130^{\circ} \mathrm{F}$ to $150^{\circ} \mathrm{F}$, whth air agitation.

3. RInse in cold running tap water for 2 minutes, if water break appears, repeat step 2 .

4. Mat dipping - this solution produces a light mat finish on copper

Dip for 5 minutes in $-10 \mathrm{H}_{2} \mathrm{SO}_{4}$ (by volume)

or until oxide is removed $10 \%$ Hydrogen Peroxide (by volume)

$$
\text { Curple Sulfate } 200_{\mathrm{g}} / 11 \text { ter }
$$

Solution at $110^{\circ} \mathrm{F}$.

5. Rinse in cold running tap water for 2 minutes.

6. If oxidation starts to form, rinse for 5 minutes in a dragout solution contalning 857 delonized $\mathrm{H}_{2} \mathrm{O}$

157 Mat Dripping Solution - described In 4 .

7. Rinse in cold running tap water for 2 intules.

8. Rinse in hot, $160^{\circ} \mathrm{F}$, delonized water for 2 minutes, with alr agitation. (Minimum resistivity 500,000 ohms.)

9. a. Electronic grade methanol rinse (1f desired).

b. Bake in oven at $250^{\circ} \mathrm{B}$.

10. Close all ports, or rrap entire part: 1st - lint free paper

2nd - new aluminum foll

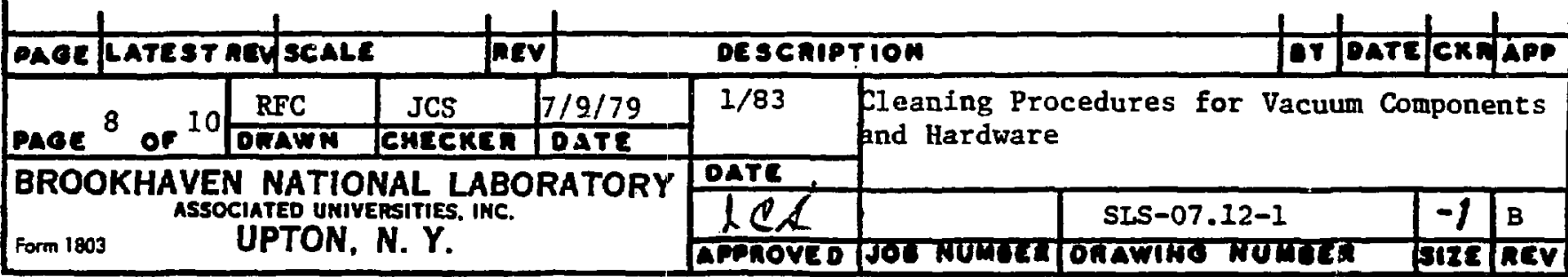


Copper cleaning

B. OFHC Copper

1. Tapor degrease in hot trichloroethane vapor for 5 minutes.

2. Soak In non-etch alkaline cleaner, Oakite 166 , for 5 minutes at $130^{\circ} F$ to $150^{\circ} \mathrm{F}$, with alr agitation.

3. RInse in cold running tap water for 2 minutes, if water break occurs repeat step 2 .

4. Immerse in $50 \%$ (by volume) $\mathrm{HNO}_{3}$ solution for 5 minutes, solution at room temperature.

5. RInse in cold running tap water for 2 minutes.

6. Repeat steps $4 \& 5$, if required.

7. Rinse in hot, $160^{\circ} \mathrm{F}$, delonized water for 2 minutes, with afr agltation. (Minimum resistivity 500,000 ohas.)

8. a. Electronic grade wethanol rlase (if and when evallable).

b. Bake in oven at $250^{\circ} \mathrm{F}$.

9. Close all ports, or wrap entire part: lot - l1nt free paper

2nd - new aluminum foll

\section{Miternate Solutions (Use this procedure)}

Step $\mathrm{A}-4$ and Step B-4.

Ose Oakite "Letal Sheen" at 35 to $50 \mathrm{z}$ by volume, room temperature. Imersion time from 10 seconds to 2 minutes depending on the amount of staln and tarnish to be removed and surface finish desired.

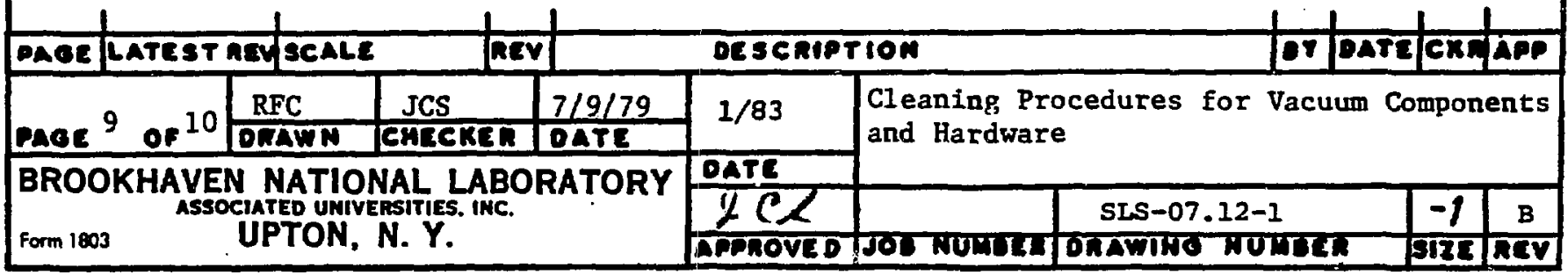


Copper Cleaning

C. OFHC Copper - bright dip

There are several "bright dips" avallable for copper. Care should be used when selecting a bright dip since some contaln phosphoric acld and other materials which might compromise the vacuum.

The following solution will be used for bright dippling copper:

1. Vapor degrease in hot trichloroethane vapor for 5 ml nutes.

2. Soak in noi-etch alkaline cleaner, Oakite 166 , for 5 minutes at $130^{\circ} \mathrm{F}$ to $150^{\circ} \mathrm{F}$, with alr agitation.

3. Rinse in cold running tap water for 2 minutes, if water break appears repeat otep 2 .

4. Dip in a solution of the following:

$$
\begin{array}{ll}
\text { Delonized } \mathrm{B}_{2} \mathrm{O} & -2 \text { liters } \\
\mathrm{B}_{2} \mathrm{SO}_{4} & -1.7 \text { liters } \\
\mathrm{HNO}_{3} & -28^{\circ} \mathrm{ml} \text { (concentrated) } \\
\mathrm{BCl}_{3} & -10 \mathrm{ml} \text { (concentrated) }
\end{array}
$$

Dip for 5 minutes at room temperature.

5. Ringe in cold running tap water for 2 minutes.

6. Rinse in hot, $160^{\circ} \mathrm{F}$, deionized water, for 2 minutes, with alr agitation. (Minfmum resistivity 500,000 ohms.)

7. a. Electronic grade methanol rinse (If and when avallable). b. Bake in oven at $250^{\circ} \mathrm{B}$.

8. Close all ports, or wrap ent1re part: lst - Ilnt free paper

$$
\text { 2nd - new aluminum foll }
$$

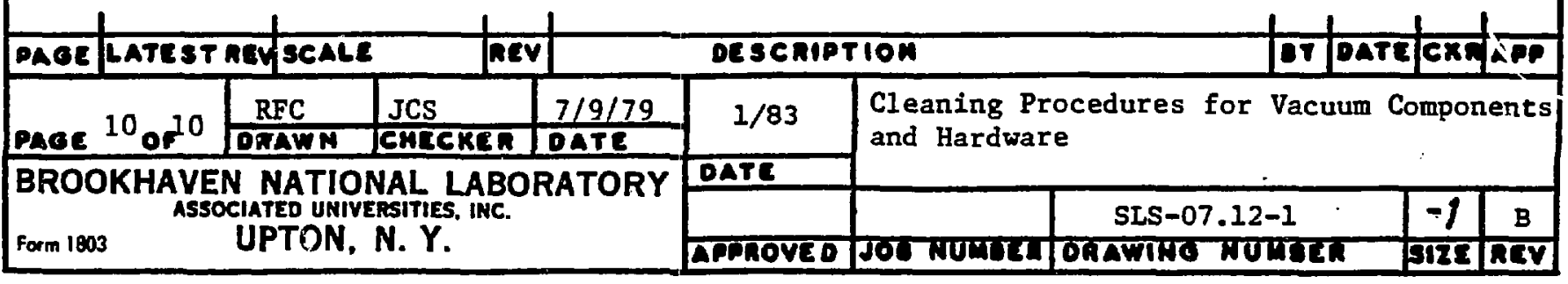


NATIONAL SYNCHROTRON LIGHT SOURCE

TECHNICAL SPECIFICATION

for

CLEANING AND FABRICATION

of

WEIDED BELLOWS ASSEMBLIES

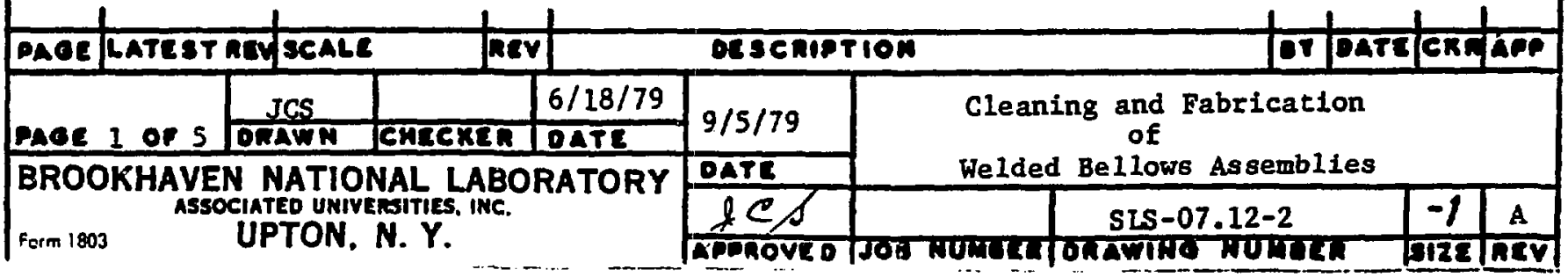


The stringent requirements which must be met by all components incorporated in the NSLS vacuum system necessitate a thorough explanation of the appropriate manufacturing standards.

The welded stainless steel bellows in particular deserve special attention to detail because of their unusual construction. Hydrocarbon contamination of surfaces or particulate matter trapped in the crevices of welded bellows convoluticins is for all practical purposes there to stay. Experience has shown that post-manufacturing chemical cleaning is of little value in removing such contamination. Bellows made with improperly handled or poorly cleaned diaphragms are rendered useless for our purpose.

The criteria for obtaining bellows which do meet the cleanliness requirements of the ultio high vacuum system is simply this:

1. Thoroughly chemically clean all component parts as specified.

2. Assemble and weld the parts without re-contaminating them.

\section{Service Requirements}

All bellows made to these standards must withstand bakeout to $250^{\circ} \mathrm{C}$ concurrent with the axial and offset stroke specified.

\section{Deviations}

No deviation from these specifications will be permitted without the prior approvall of the NSIS.

\section{Chemical. Cleaning}

Prior to assembly, all metal parts and fixtures must be thoroughly chemically cleaned. The following process is standard practice at NSIS and is provided here as a gulde to successful cleaning.

End fittings shall be cleaned in the same manner as diaphragms. Handle with white gloves. Parts need only to be cleaned once, just prior to welding. By handling in a manner which does not re-contaminate them, they will remain in a clean state and not be cause for rejection.

1. Pleces shall be suspended on a stainless steel holding fixture in such a way that diaphragms or parts do not touch each other.

2. Degrease in trichloroethane vapor degreaser. If not avallable, parts may be cleaned in the ultrasonic tank using trichloroethane or freon TF.

3. Soak in non-etch alkaline cleaner, Oakite 166 , for 5 minutes at $130^{\circ} \mathrm{F}$ to $150^{\circ} \mathrm{F}$, with air agitation.

\begin{tabular}{|c|c|c|c|c|c|c|c|c|c|c|c|}
\hline DAOE I & ATEST & ADYscALE & hev & & orsent & & & ET & DATE & ERE & APP \\
\hline \multirow{2}{*}{\multicolumn{2}{|c|}{ PAce 2 of 5}} & JCS & & $6 / 18 / 79$ & \multirow{2}{*}{$9 / 5 / 79$} & \multirow{3}{*}{\multicolumn{4}{|c|}{$\begin{array}{l}\text { Cleaning and Fabrication } \\
\text { of } \\
\text { Welded Bellows Assemblies }\end{array}$}} & & \\
\hline & & ORANN & CALCKER & DATE & & & & & & & \\
\hline \multirow{2}{*}{\multicolumn{5}{|c|}{$\begin{array}{l}\text { BROOKHAVEN NATIONAL LABORATORY } \\
\text { ASSOCIATEO UMIVERSITIES. INC. } \\
\text { UPTON. N. Y. }\end{array}$}} & DATE & & & & & & \\
\hline & & & & & & \multicolumn{4}{|c|}{ SLS-07.12-2 } & -1 & A \\
\hline
\end{tabular}


4. RInse in cold running tap water for 2 minutes. If water break appears repeat step 2 .

5. Pickle in Eydro Fluoric-Nitric acid solution, at room temperature $\left(70^{\circ} \mathrm{F}\right)$ for 1 to 2 minutes, with air agitation.

$$
\begin{aligned}
& \text { Hydrofluoric acid } 48 \%-33 \% \text { by volume } \\
& \begin{array}{ll}
\text { Nitric acid, } 42^{\circ} \text { Baume - } 33 \% \text { by volume } \\
\text { Distilled water } & -33 \% \text { by volume }
\end{array}
\end{aligned}
$$

Immersion time shall be sufficient to clean surface of scale and oxide. Care should be taken to avoid overetching.

6. Rinse in cold running tap water for 2 minutes.

7. Rinse in hot, $160^{\circ} \mathrm{F}$, deioxized water for 2 minutes, with air agitation. (Minimum resistivity 5000,000 ohms).

8a. Electronic grade methanol rinse.

b. Blow dry with dry nitrogen gas, preferably taken from an evaporated liquid source. Dry, high purity (99.99\%) water pumped nitrogen bottled gas may also be used.

9. Close all ports, o1 wrap entire part: lst - lint-free paper 2nd - new aluminum foil Place part in polyethylene, non-static bag, pumpout and backfill with dry nitrogen and seal.

\section{Handling and Assembly}

When unwrapping cleaned diaphragms in preparation for weldirig, they shall only be handled by clean, white, nylon gloves. Gloved hands which touch cleansed parts must touch nothing else!

The welder must be alert at all times not to touch his face, clothing, tools, bench, stools, etc. Actuation of switches, adjustment of welding torch, etc. must be performed with gloves removed. Gloves which do come in contact shall be immediately replaced with a new pair. New gloves shal $\bar{I}$ also be used at the beginning of each shift and following period breaks.

All those parts of the welding apparatus which come in contact with, or even close proximity to the diaphragms being welded, must be thoroughly cleaned and wiped down with approved solvent and the lint free tissue.

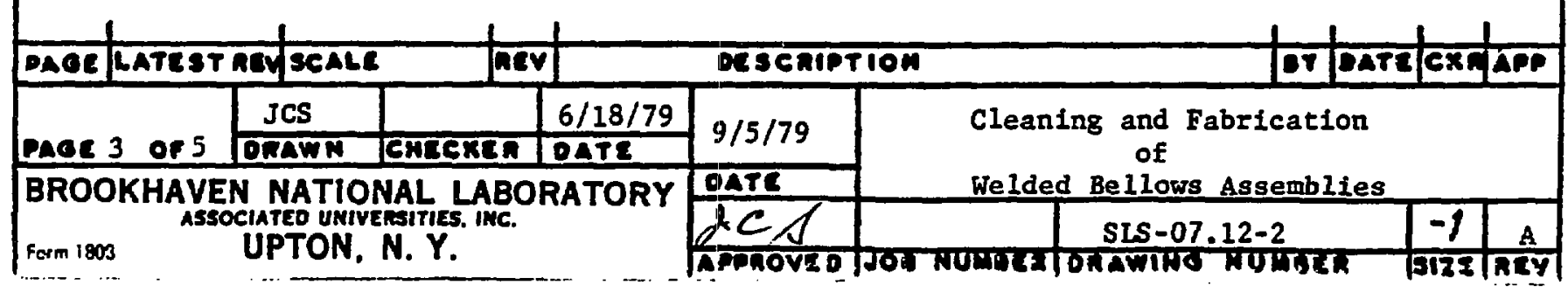


Trichloroethane or Freon TF may be used. This will be followed by wiping down with another tissue using electronic grade methanol.

The welded convolution shall be re-wrapped in new tissue immediately following welding and inspection. The handing criteria for assembly of the convolutions, inserting the spacer rings, welding the core and associated steps shall be the same as for welding the diaphragms, namely: using new gloves at the same intervals; gloved hands which touch the bellows parts touch nothing else; machinery which comes in contact with or close to the bellows shall be wiped down with the same solvent procedure as before. The copper spacer rings must be thoroughly cleaned to the same standards as the diaphragms with one exception: the Pickle/Passive step 5 is omitted and a copper cleaning solution such as: Enthone "Actane 36" or MacDermid Metex chemical polish - "BCB" substituted in its place. All other cleaning parameters remain the same. All handling, welding, and leak testing shall take place in a Clean Room which follows current vacuum industry practice for ultra high vacuum cleanliness.

\section{Weld Quality and Workmanship}

Unless otherwlse approved, all welding shall be by tungsten inert gas (TIG) fusion process without the use of filler rod.

It is important to state that leak tightness alone is not the only criterion for the acceptability of weld quality. The appearance and workmanship of the welding is equally important. All weld bead shall be continuous and uniform in height and width.

\section{Material Certification}

Vendor shall furmish original source certifications: physical and chemical test reports, of all materials which are a part of the final assembly. In the case where these reports are not available, the vendor shall provide evidence that the materials being used are in fact those specified.

\section{End Fittings}

All bellows end attachments such as collars, flanges, weld rings, etc., shall be made from solid stock material, either plate, sheet or forgings. No cast material will be acceptable. End fittings shall be free of any file marks, dents or scratches.

\section{Leak Testing}

Following welding, bellows shall be leak tested using a mass spectrometer helium leak detector. Unwrapping, handling, and rewrapping of the bellows during leak testing shall also follow the previous glove restrictions: periodic glove changes; no contamination transfer, etc. Use of the leak detector including periodic maintenance shall conform to the manufacturer's recommendations. During testing, the helium nozzle must be directed at the gap between the spacer wires or chill rings inserted between each convolution so that the gas will enter the void between the convolutions. No indication of leakage is permitted when tested by a leak detector

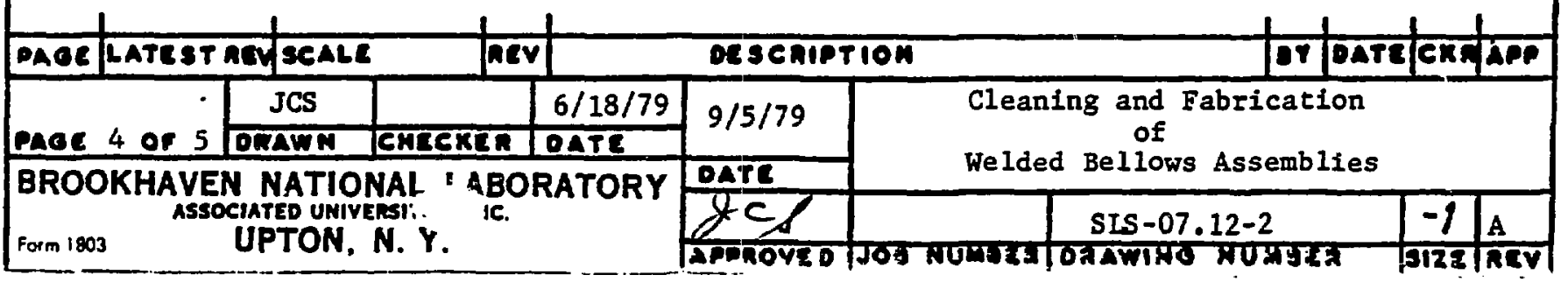


with a minimum helium sensitivity of $2 \times 10^{-10} \mathrm{std} \mathrm{cc} / \mathrm{sec}$ per division.

The helium leak detector shall not be situated within the clean room proper because of the contamination due to mechanical pump rubber belts and exhaust. The roughing pump used to evacuate the bellows prior to leak testing shall be "trapped" to prevent passage of oil vapors into the bellows.

The internal vacuum plumbing which joins the test plate, the leak detector and roughing pump shall be thoroughly cleaned with approved solvents prior to testing the first bellows.

0-rings or rubber flat stock used as a temporary seal on the ends of the bellows for the purpose of leak testing shall be new rubber, clean and dry. No lubricants or grease of any kind are permitted. Experience has shown that low durometer 0 -rings or pure gum rubber sheet works satisfactorily if the seal loading is adequate.

\section{Shipment}

Each bellows which is accepted shall be completely wrapped with new aluminum foil imediately following leak testing. It will then be placed in a new polyethlene bag and the open end heat sealed. This package will then be placed in its own corrugated paper carton. Shipment of individually boxed bellows may be made in a larger corrugated cardboard carton.

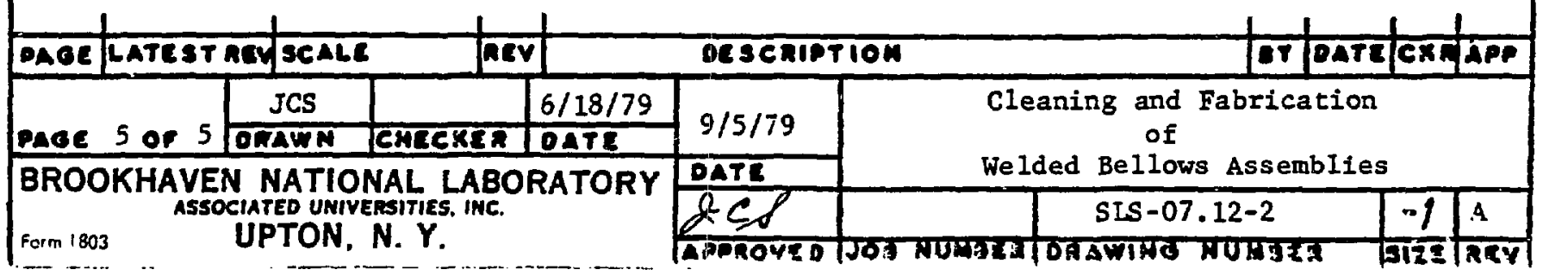


NATIONAL SYNCHROTRON LIGHT SOURCE

TECHNICAL SPECIFICATION

for

THERMISTOR GAUGE ATMOSPHERE TO 1 MICRON

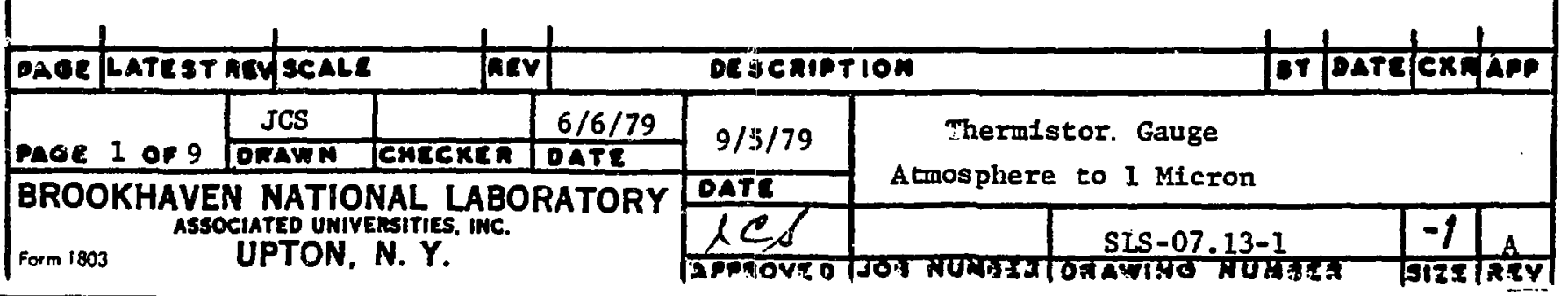


CONTENTS

Dimensional drawing of gauge assembly.

Gauge Calibration curves for:

Argon

Neon

ㅂelium

Nitrogen

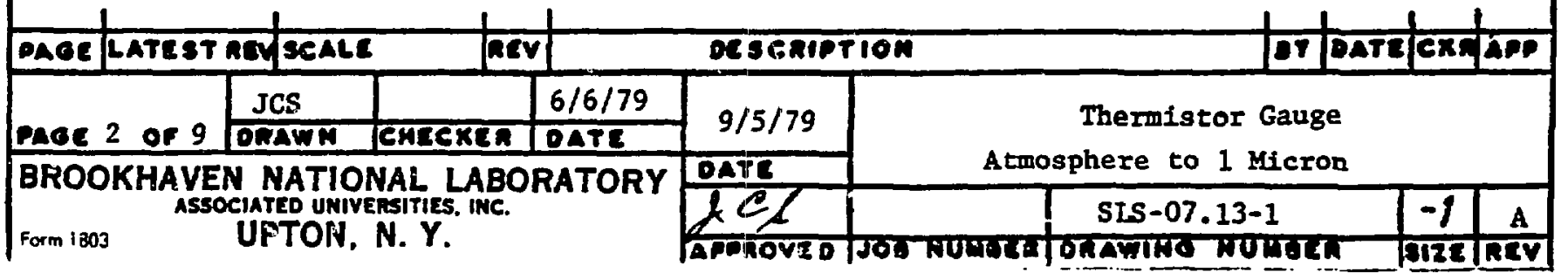




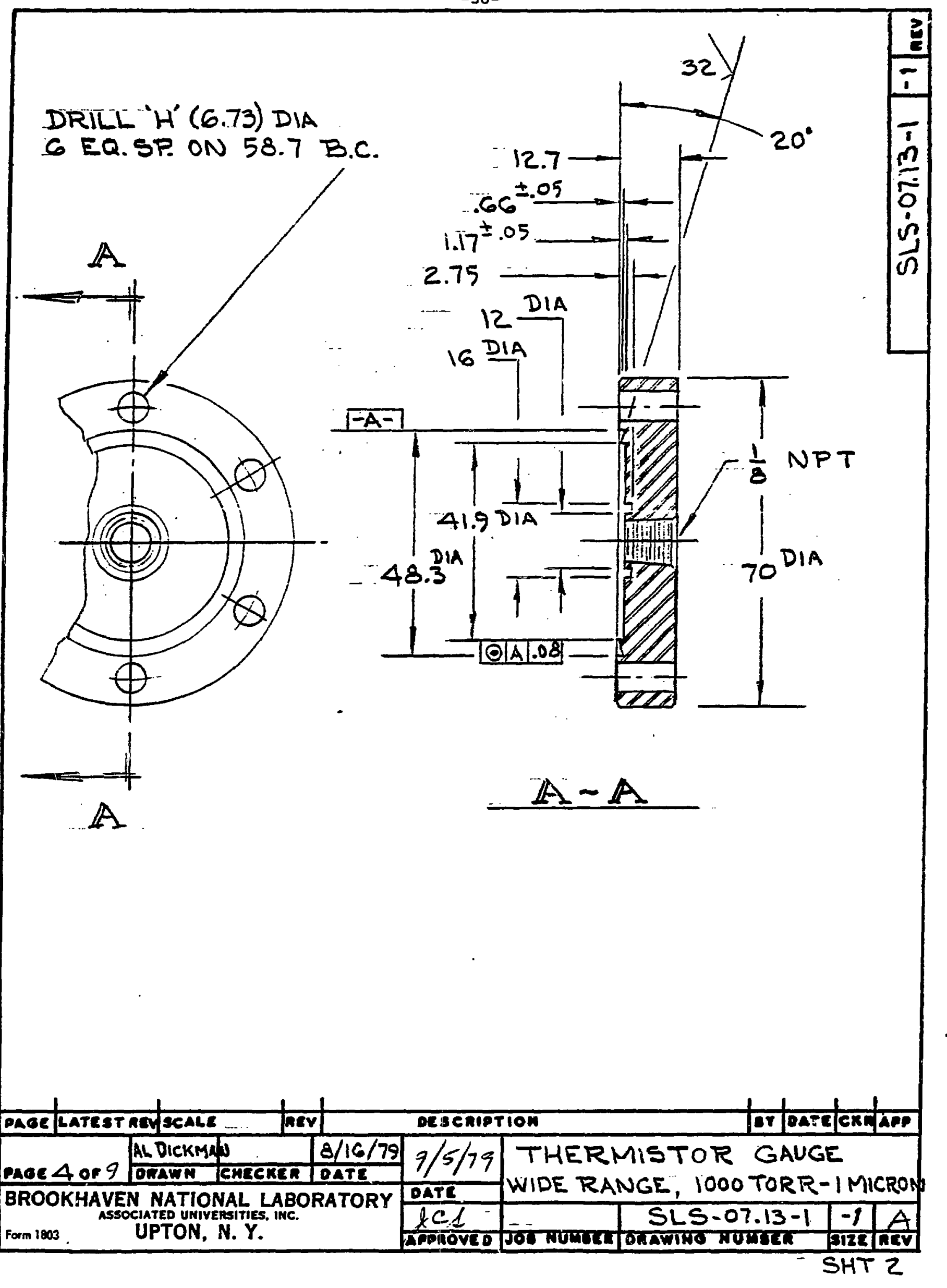




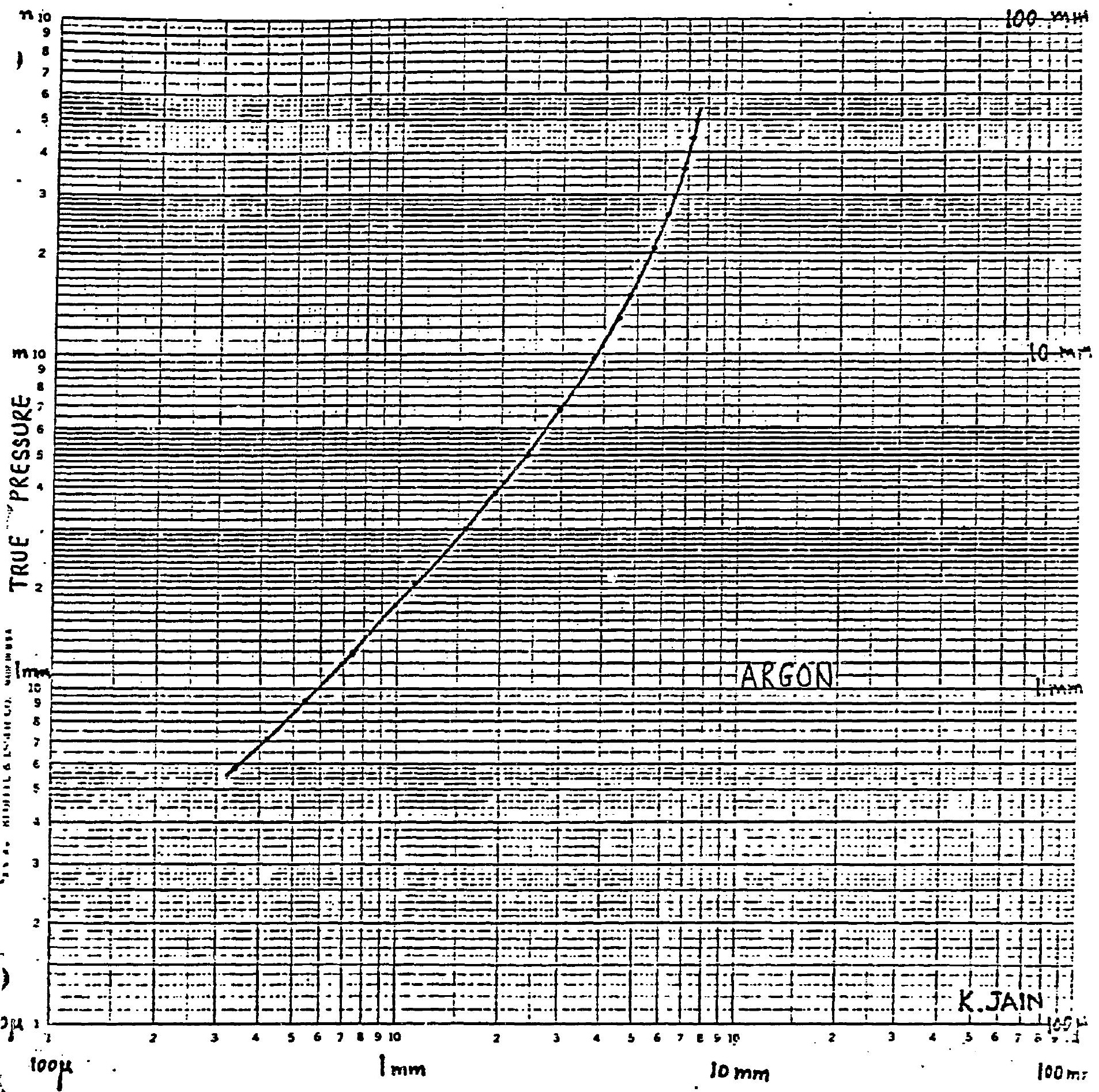


20 -

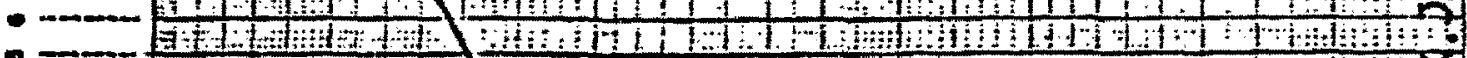

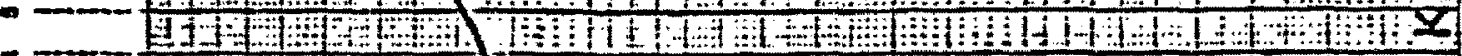

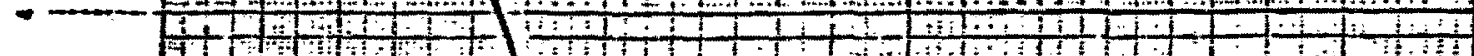

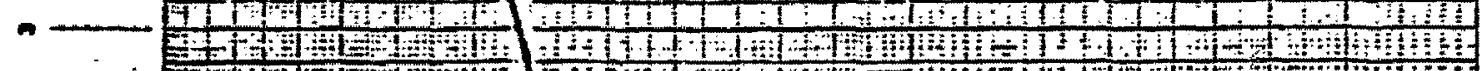

$\omega$

स+F

F

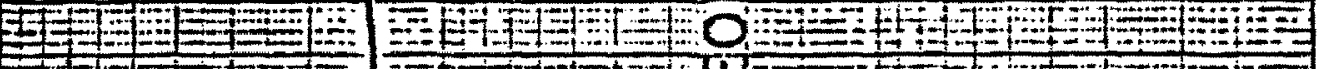

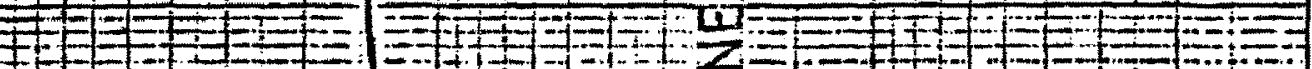

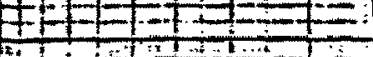

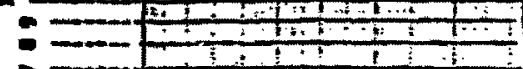

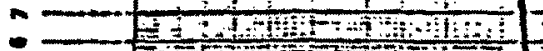

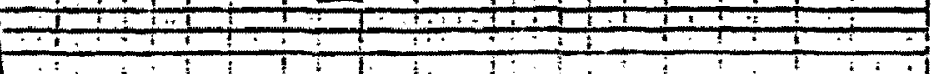

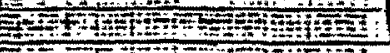

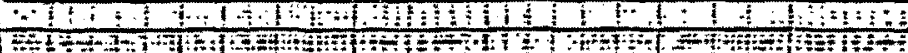

El

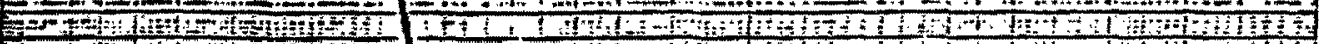

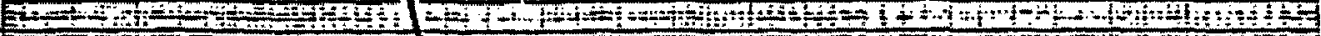

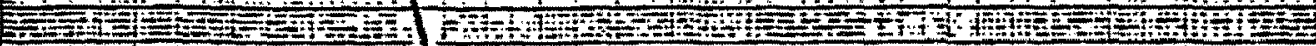

는 $=219$

$12=12=1$

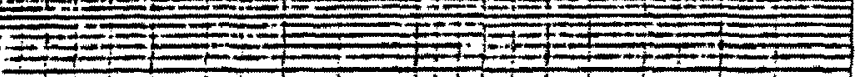

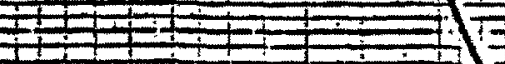

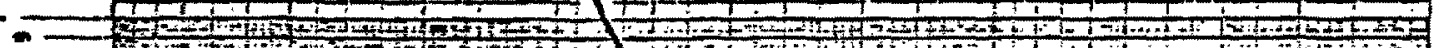

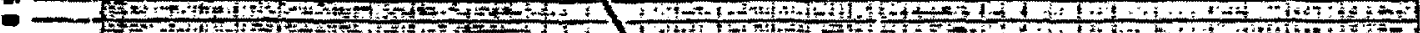

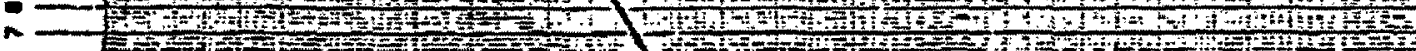

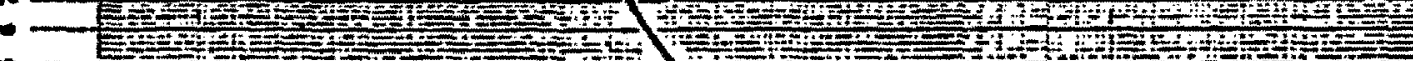

$-7-6$

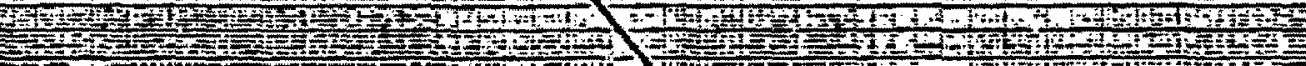

-

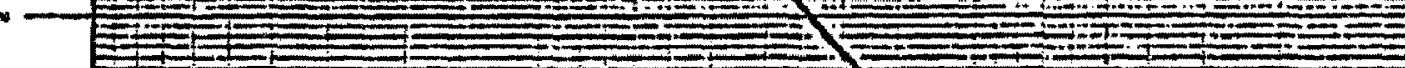

$1+12=$

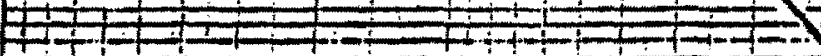

$=1$

$+2=$

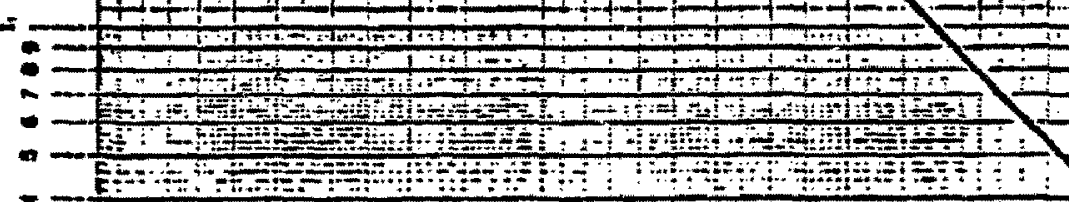

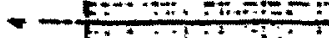

$-1$

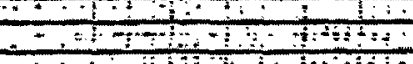

1

$+1+1+1$

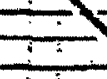

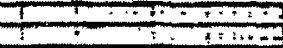

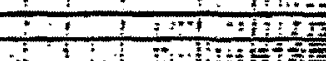

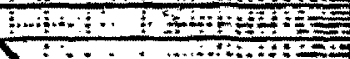

$\because: 1: \ldots+4: \div$

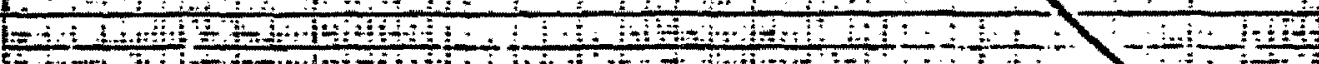

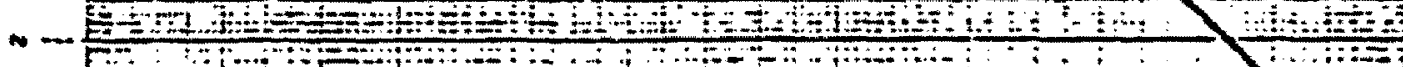

E E

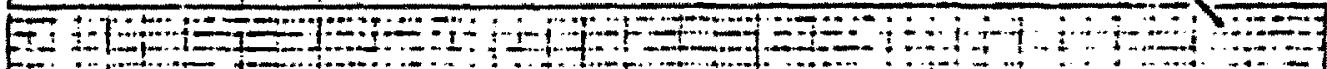

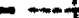

-

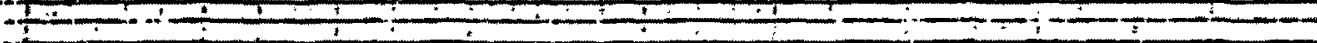

$-1$

-

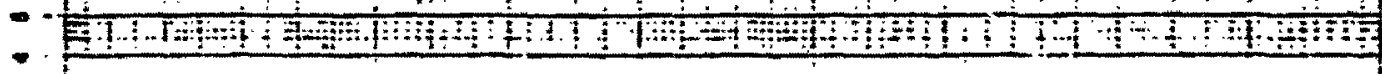

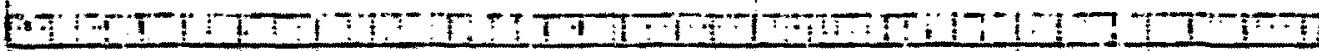

m.

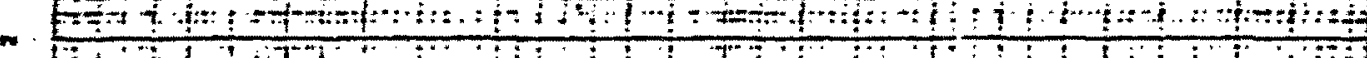

E

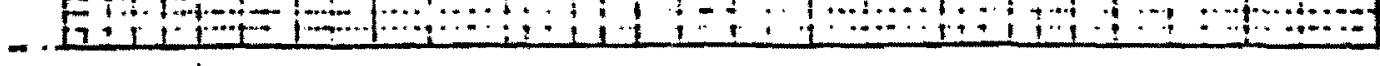

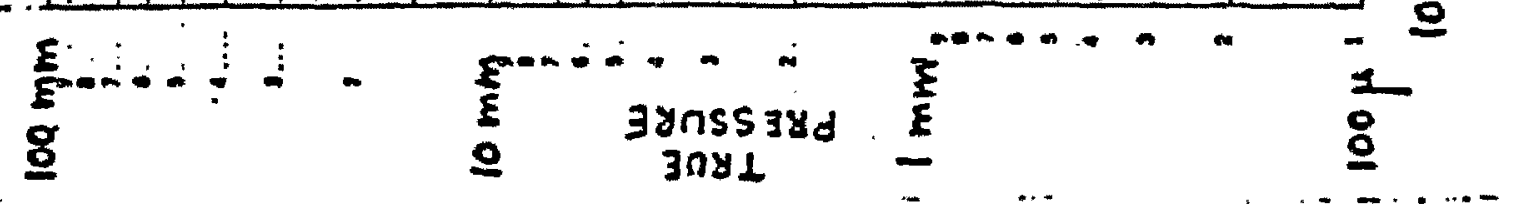

$\frac{2}{8}$ 


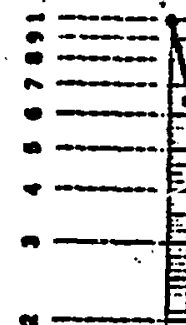

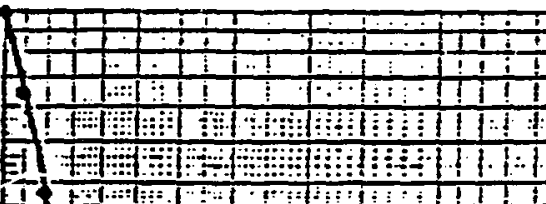

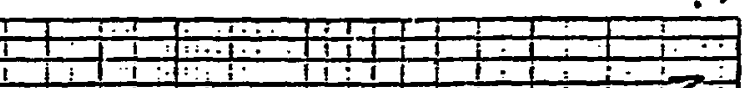

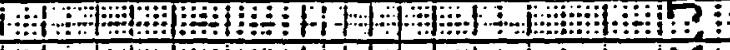
If 2- $\mathrm{f}$ J F 9.1

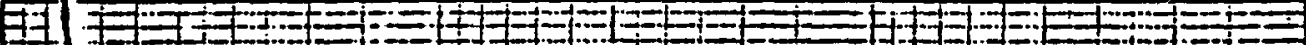

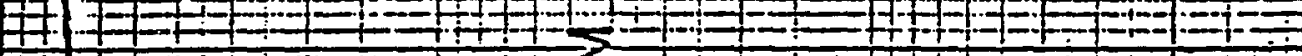

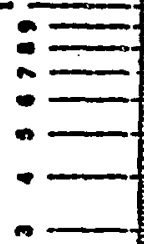

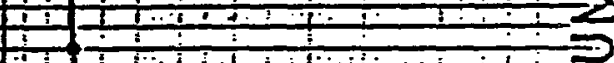

$\rightarrow-$

j- 1 -

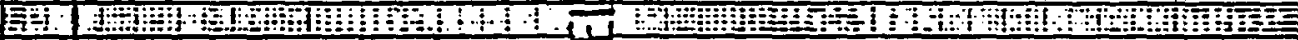
E

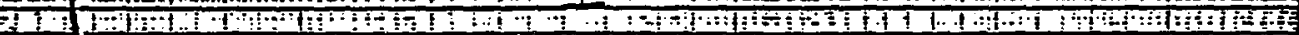

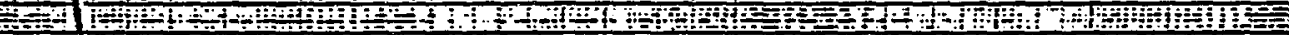

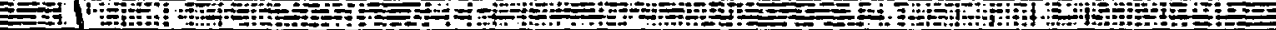

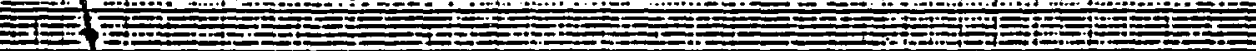

$\cdots+10$ $+1+2=$ $+1=1=$

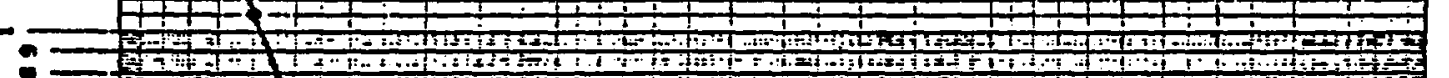

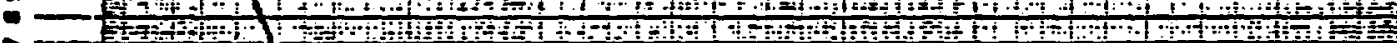

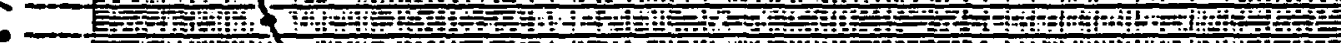

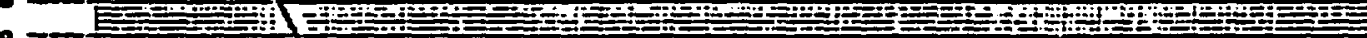

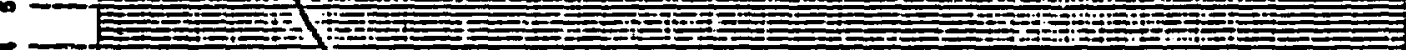

$-\longrightarrow$ 1.

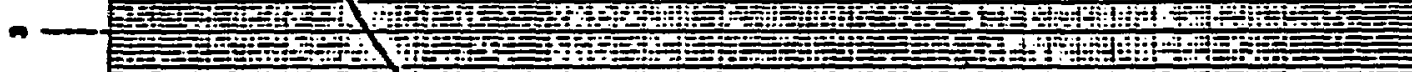

$\infty-1$

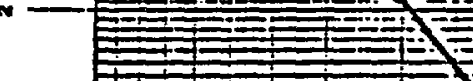

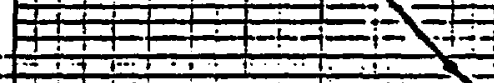

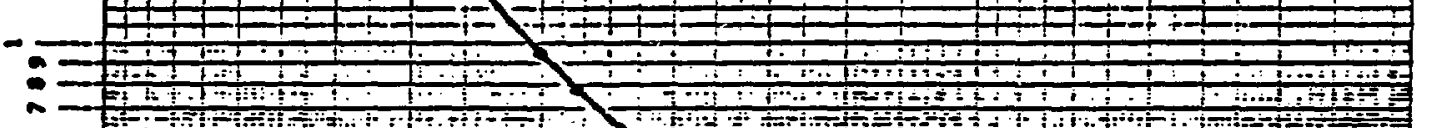

0 -

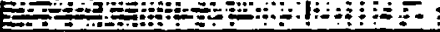

1

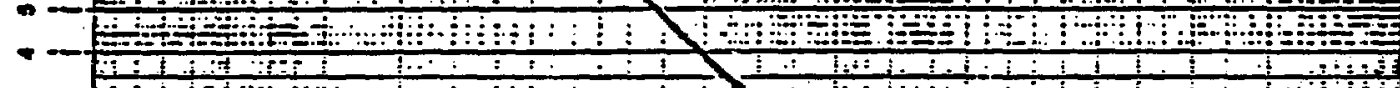

ค -

F.

$\omega-\infty$

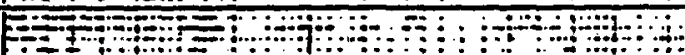

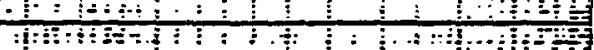
年:

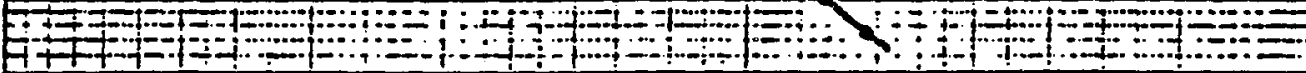

$-$

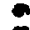

م-

- -

$\rightarrow$

-

$-$

๑.

F! ! +

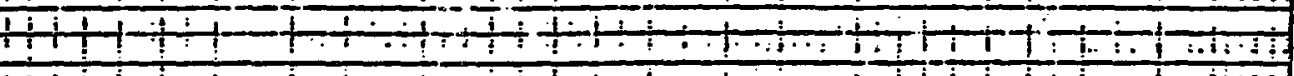

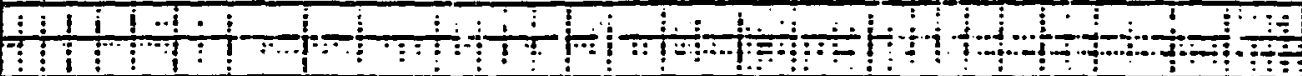

-

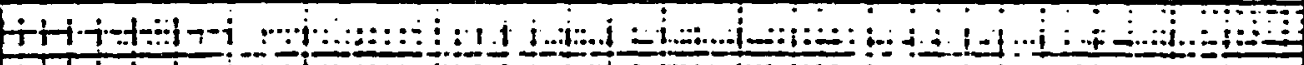

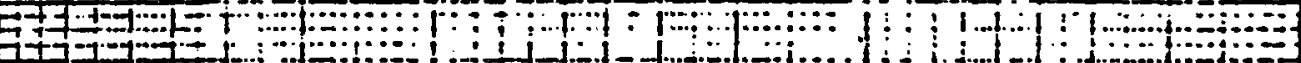

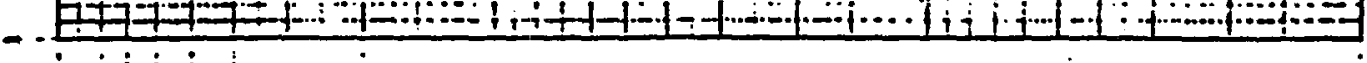
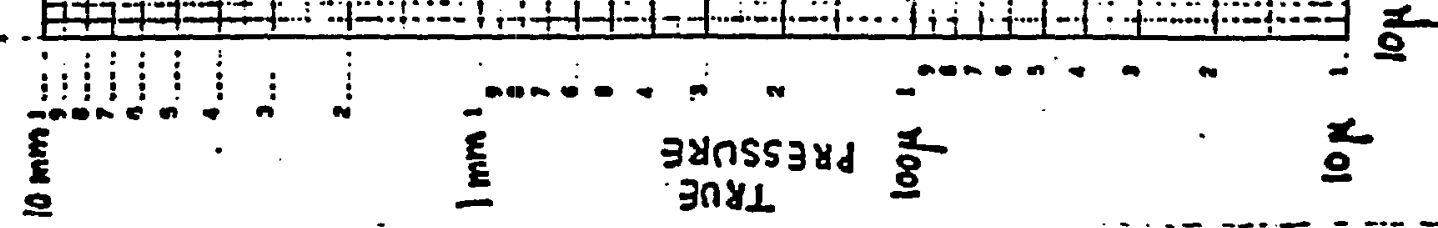


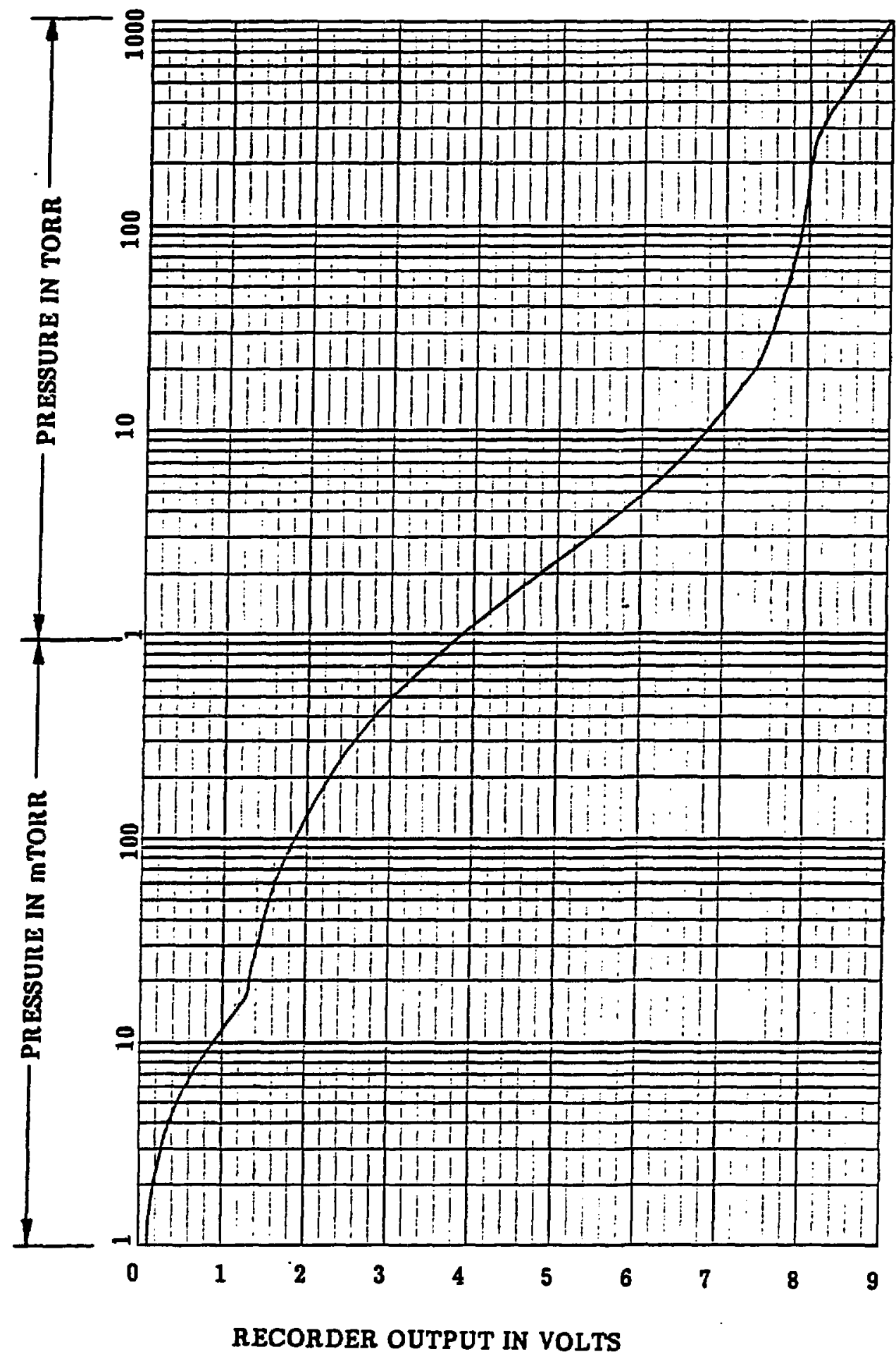

FIG. 4-4 NITROGEN PRESSURE VS. ANALOG CONTROLLER RECORDER OUTPUT VOLTAGE 


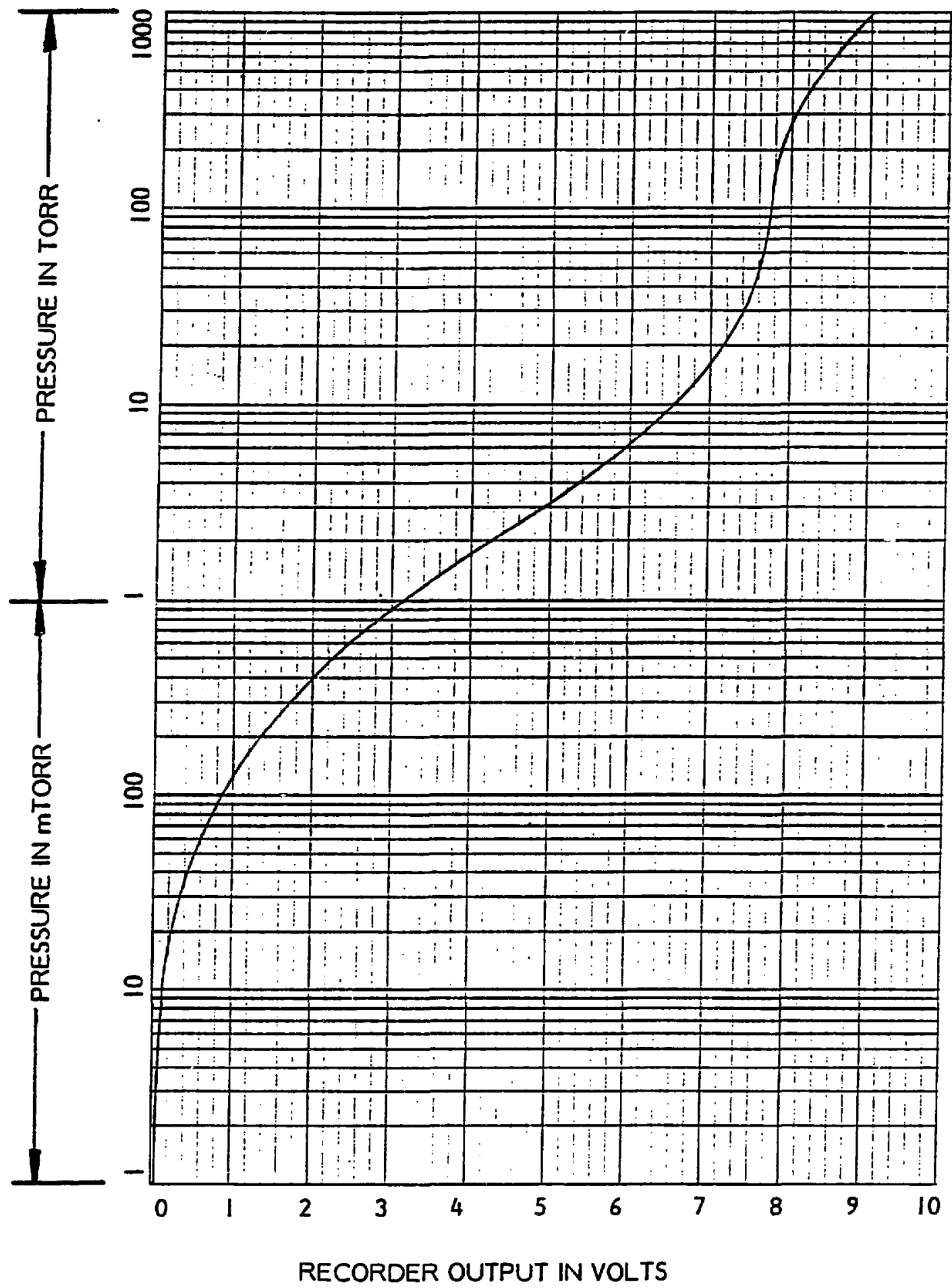

FIG. 4-5 NITROGEN PRESSURE VS. DIGITAL CONTROLLER RECORDER OUTPUT VOLTAGE 
NATIONAL SYNCHROTRON LIGHT SOURCE

TECENICAL SPECIFICATION

for

THERMISTOR GAUGE ATMOSPHERE TO I MICRON

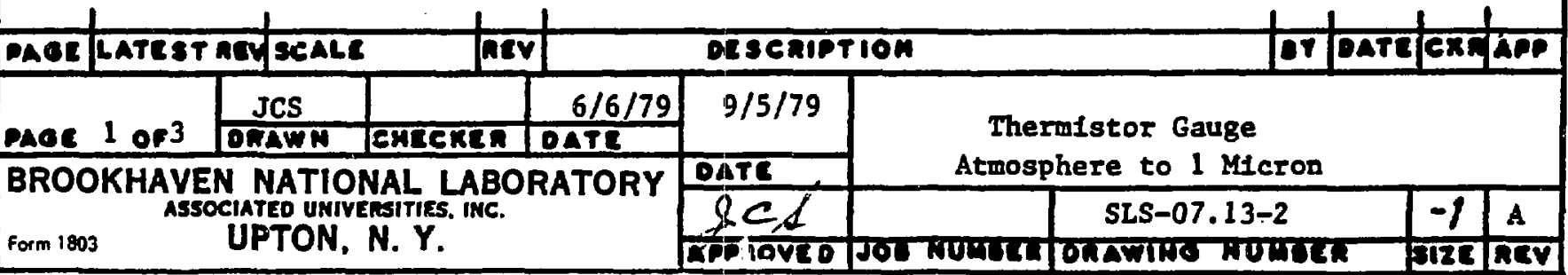




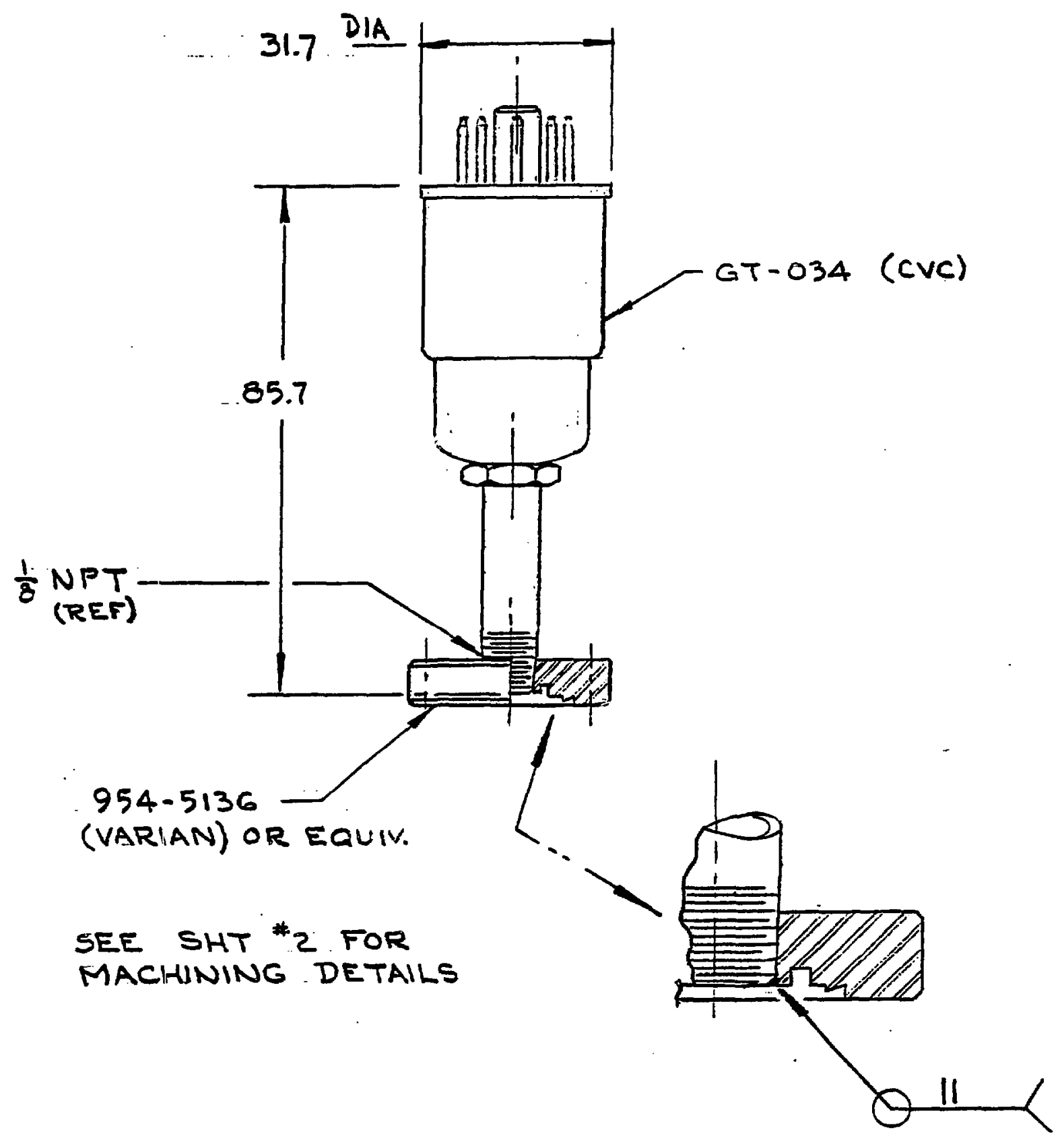

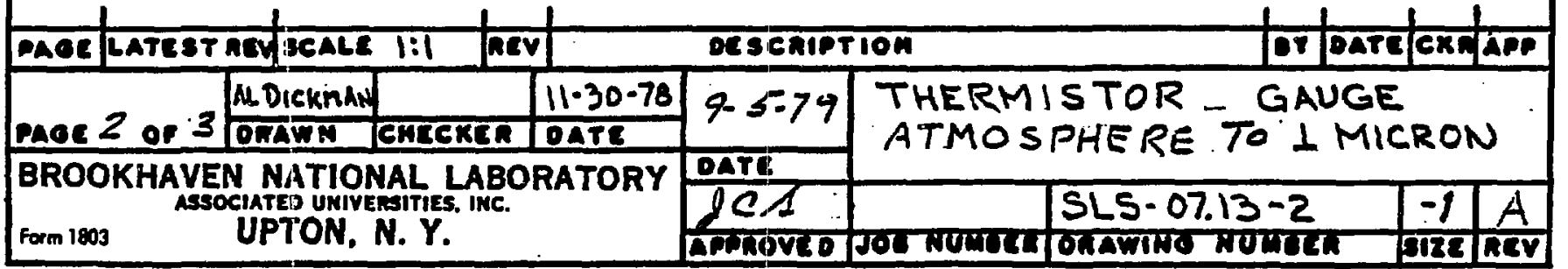




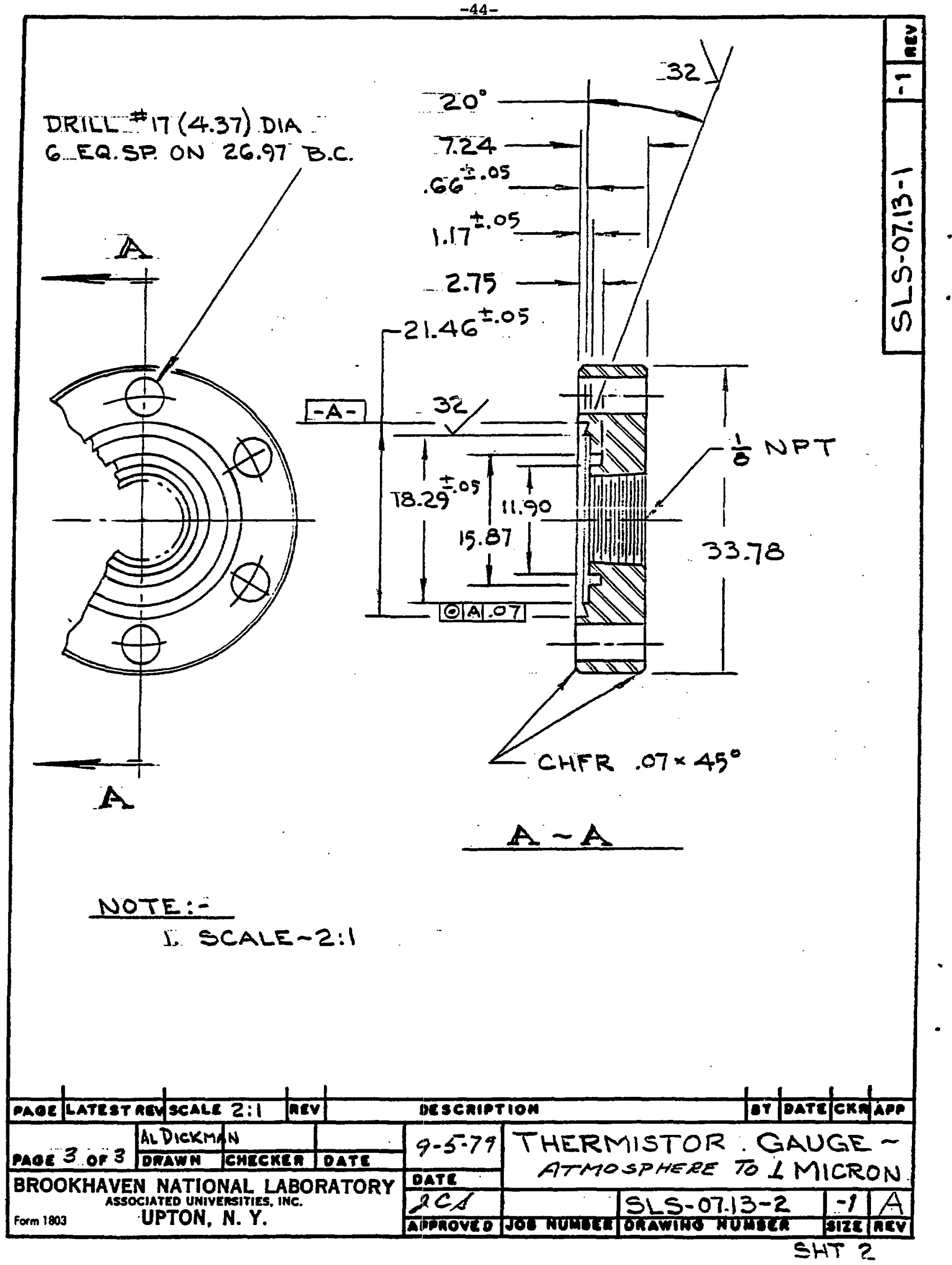


NATIONAL SYNCHROTRON LIGHT SOURCE

TECHNICAL SPECIFICATION

for

ION GAUGE - COID CATHODE $10^{-3}$ TORR to $10^{-8}$ TORR

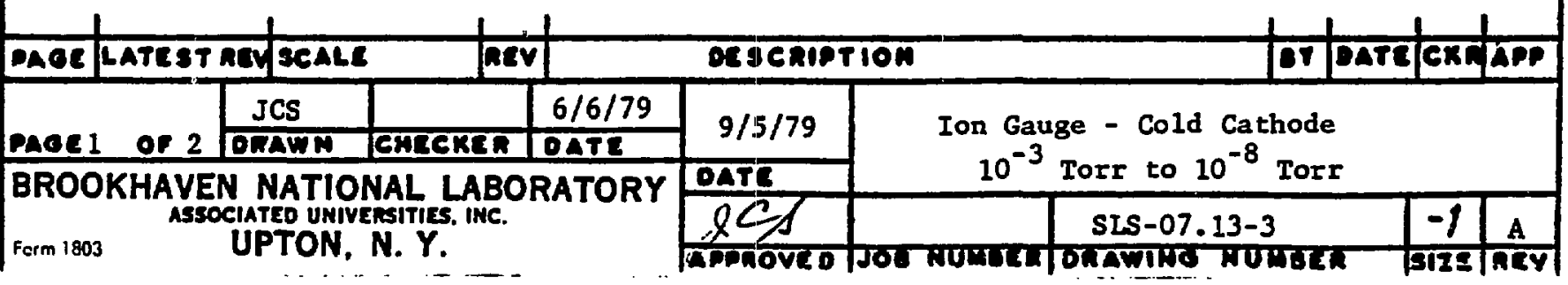


MODEL;GPH-001 \# 06110 DISCHARGE

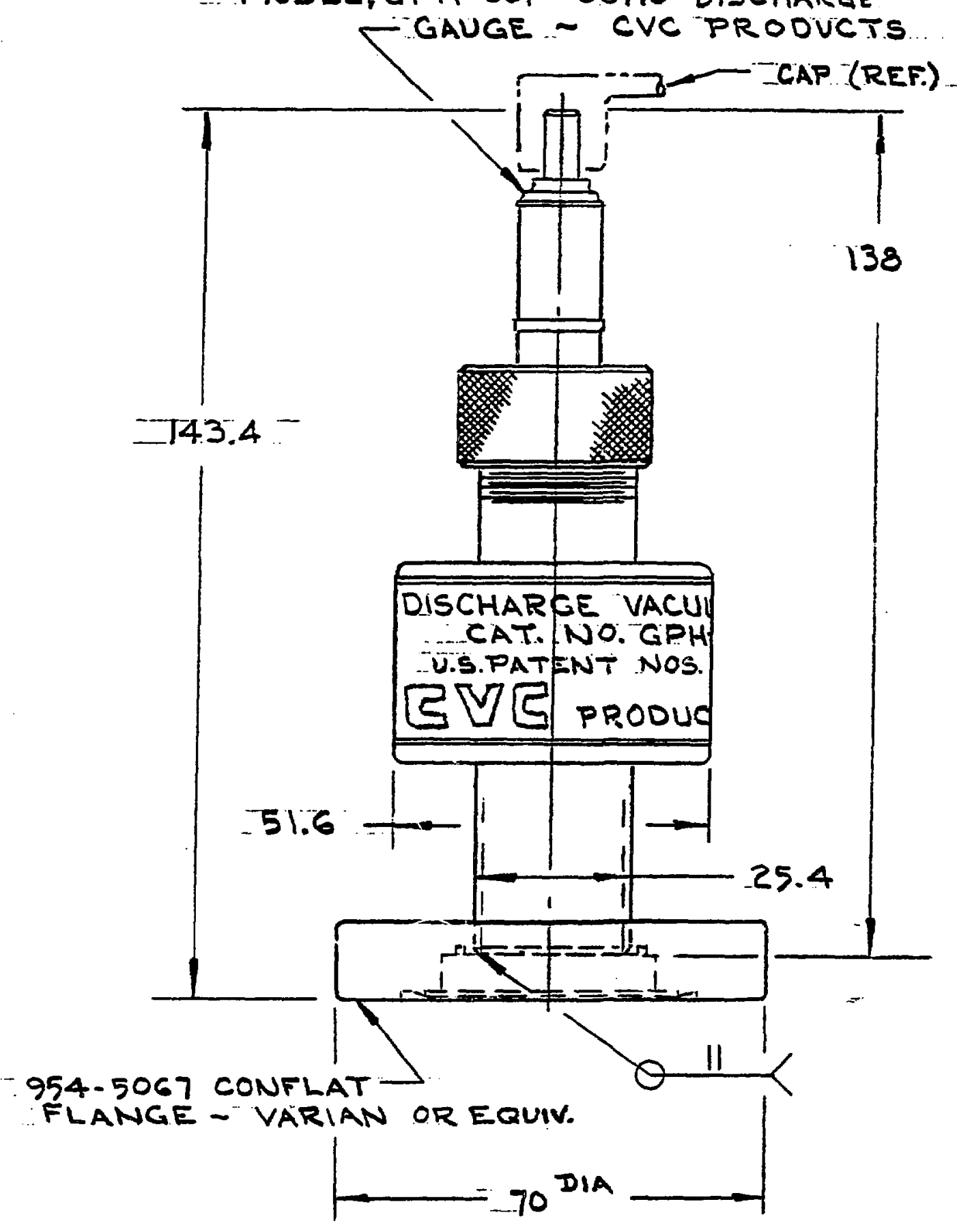

$954-5067$ CONFLAT

FLANGE VARIAN OR EQUIV.

\section{-}

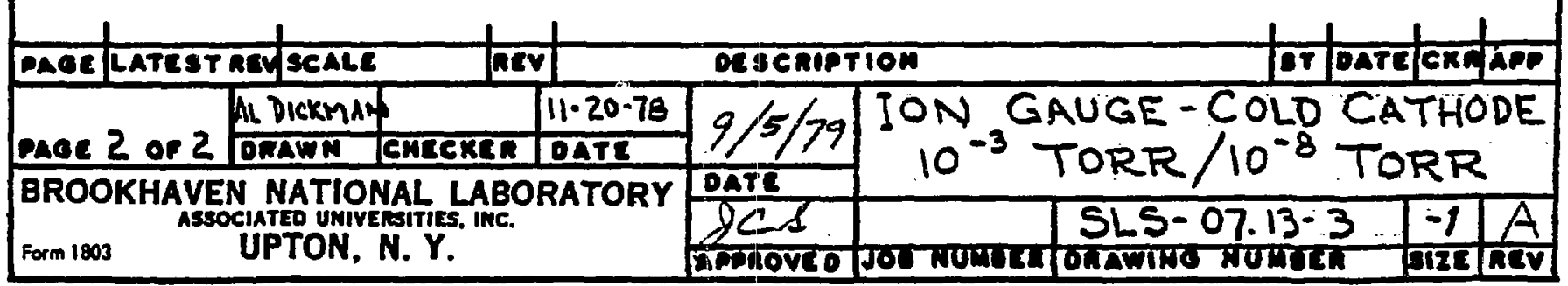


NATIONAL SYNCHROTRON LIGHT SOURCE

TECHNICAL SPECIFICATION

for

ION GAUGE - HOT FIIAMENT $10^{-4}$ TORR to $10^{-11}$ TORR

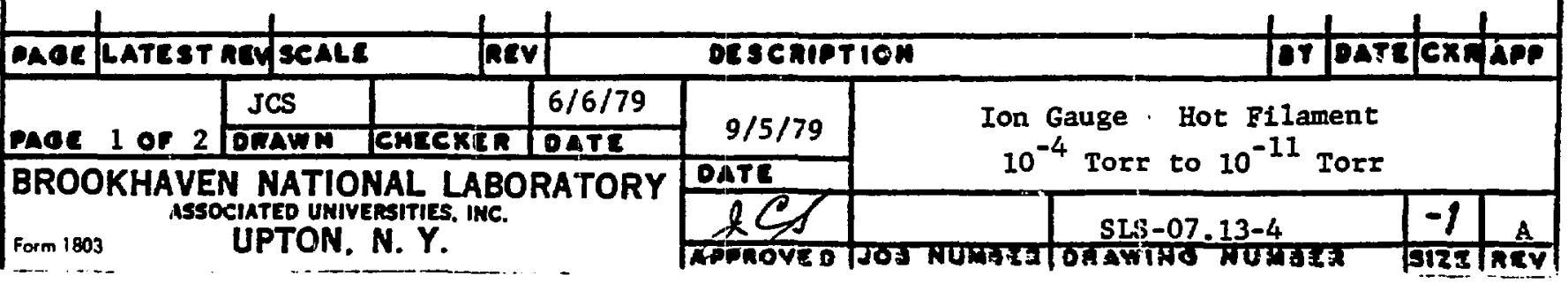




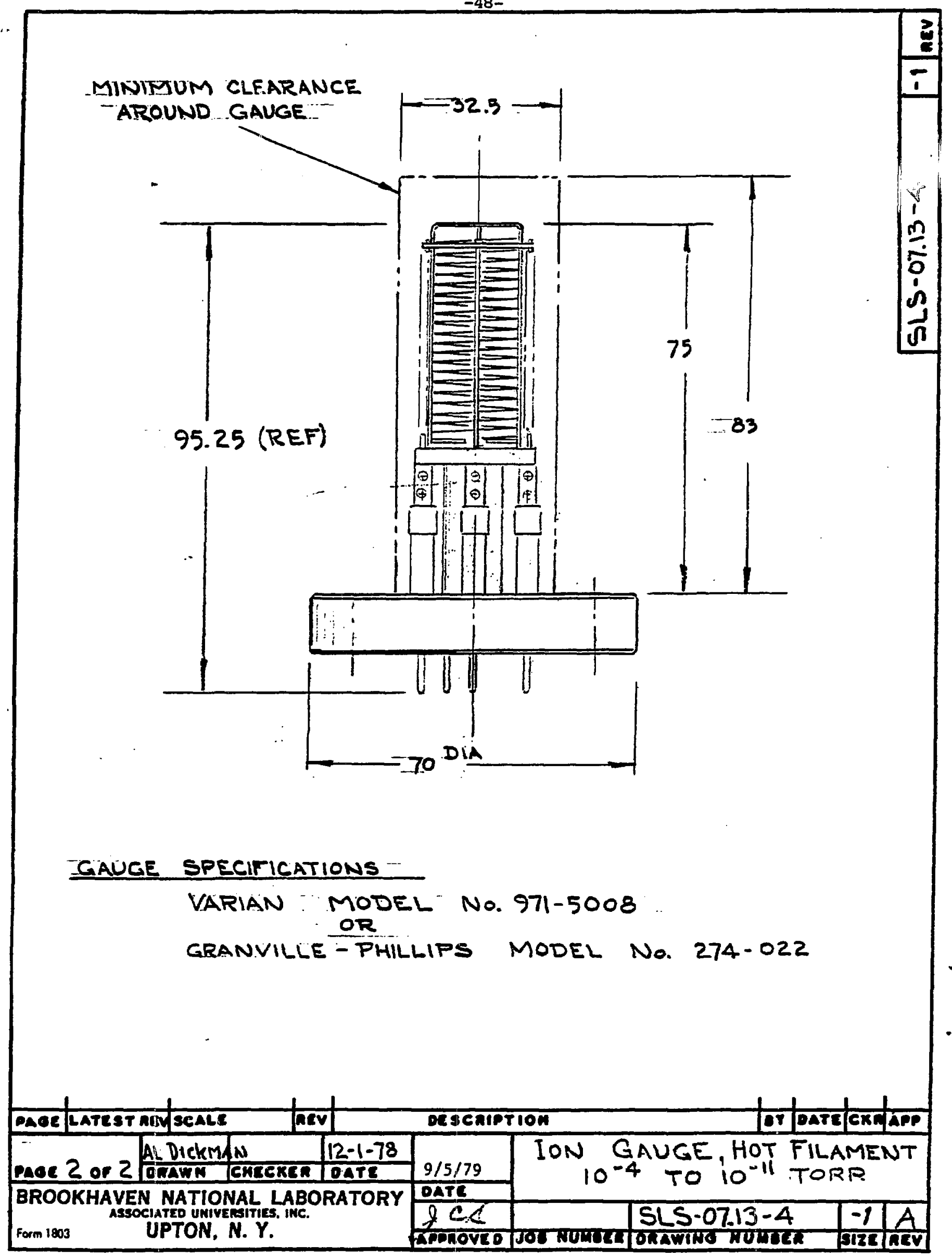


The following table lists relative gauge sensitivities for various gases. The values are derived by empirical methods substantiateo - measurements reported in litcrature. The multiple values found in the toble represent several difierent raferences. This ...le has been compiled and published by Robert L. Summers of Lewis Research Center. NASA Technical Note TN D.52as. National Aeronautics and Space Administration, Washington, D.C., June $196 \Xi$.

- To convert readings from the ionization gauge control (normally calibrated for nitrogen) divide the indicated pressure by the number listed in the third column for the particular gas $\left(S / S_{n_{2}}\right)$.

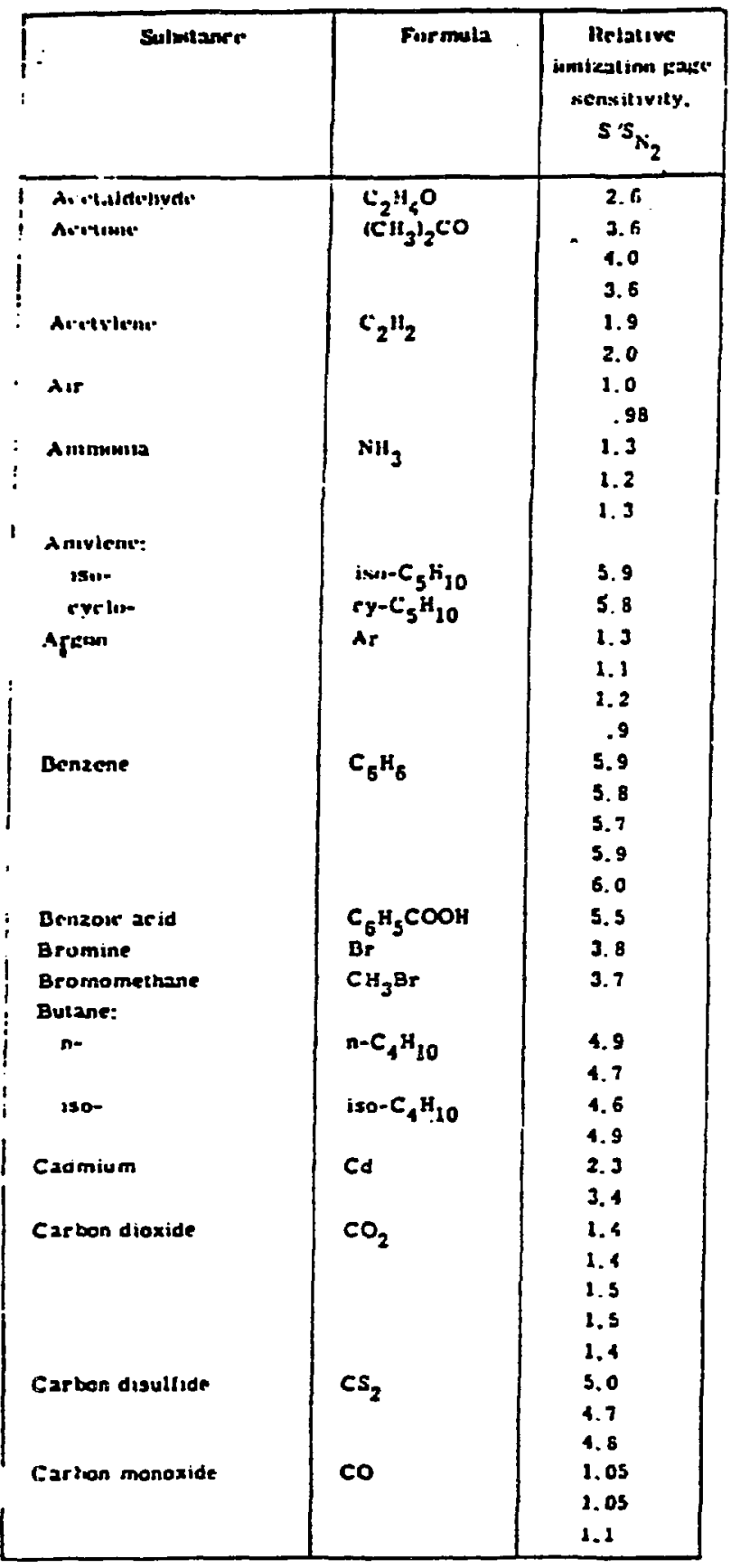

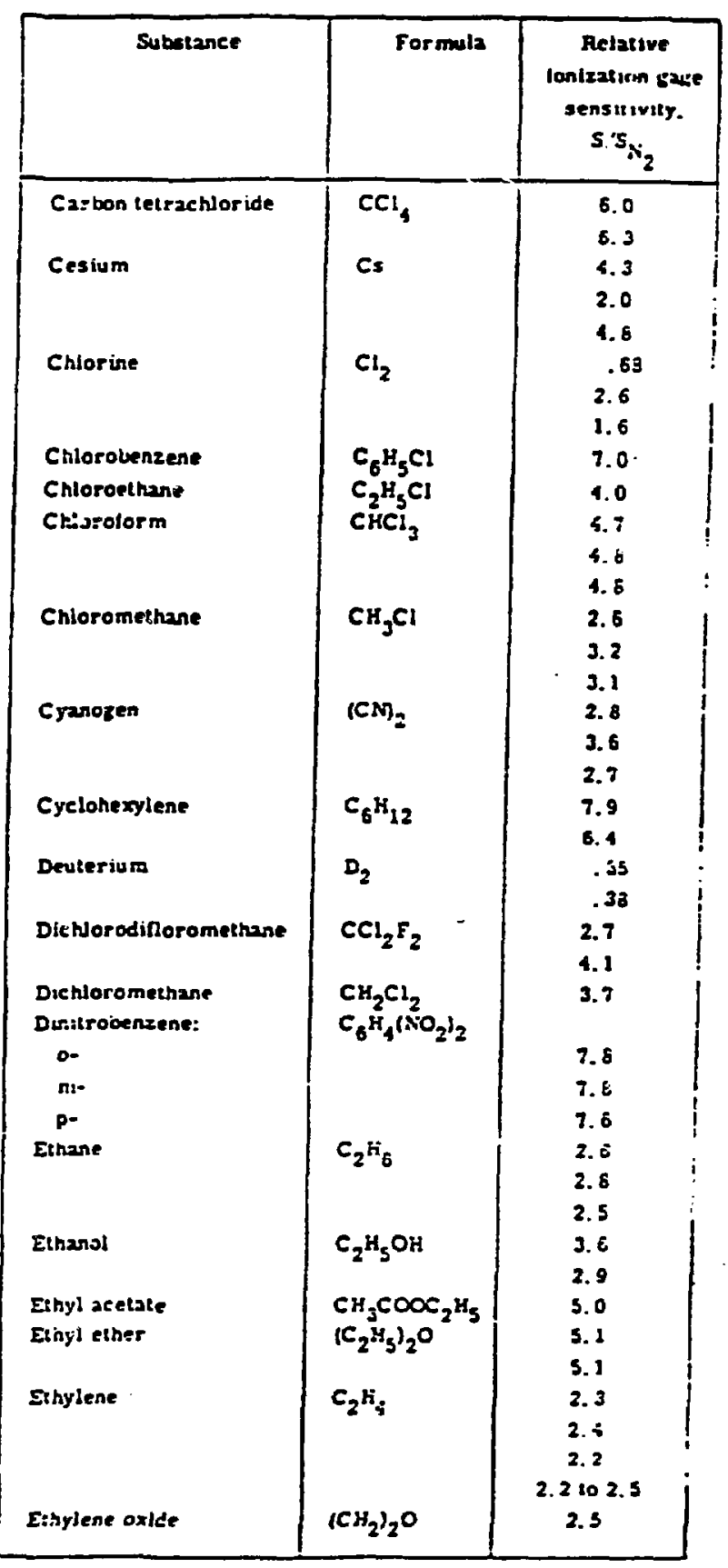




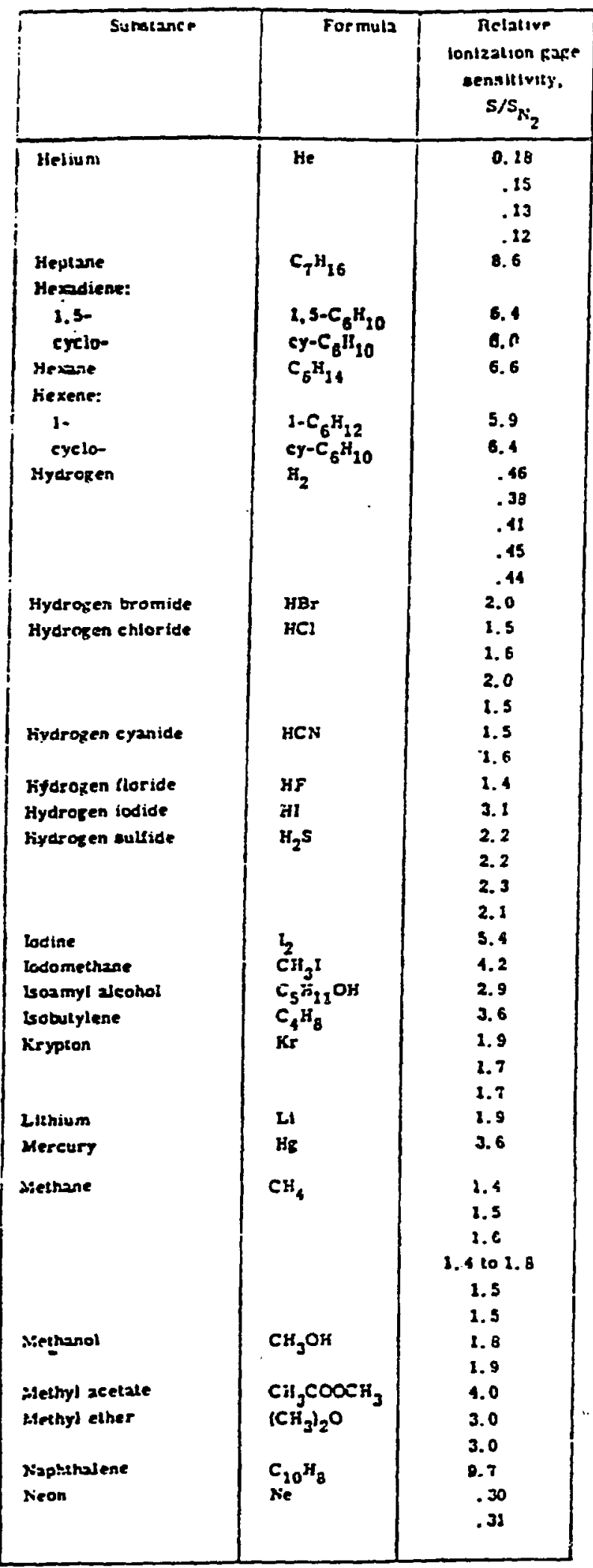

\begin{tabular}{|c|c|c|}
\hline Substance & for niula & 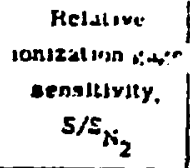 \\
\hline Nitsotenzent & $\mathrm{C}_{6} \mathrm{H}_{5} \mathrm{NO}_{2}$ & 7.2 \\
\hline Nurogen & $r_{2}$ & 1.0 \\
\hline Nisrololuene $(0-, \mathrm{m}-, \mathrm{p}-)$ & $\mathrm{C}_{6} \mathrm{H}_{4} \mathrm{CH}_{3} \mathrm{HO}_{2}$ & 0.5 \\
\hline Niterie oxlde & No & $\begin{array}{l}1.3 \\
1.2 \\
1.0\end{array}$ \\
\hline Nilsous oxjde & $\mathrm{N}_{2} \mathrm{O}$ & $\begin{array}{c}1.5 \\
1.7 \\
1.7 \\
1.3102 .1\end{array}$ \\
\hline Oxyzen & $\mathrm{O}_{2}$ & $\begin{array}{r}1.0 \\
1.1 \\
.9 \\
. \quad .9\end{array}$ \\
\hline Pentane: & & \\
\hline$n-$ & $n-C_{5}{ }^{H} 17$ & $\begin{array}{l}6.2 \\
6.0 \\
5.7\end{array}$ \\
\hline $\begin{array}{l}\text { iso- } \\
\text { neo- }\end{array}$ & $\begin{array}{l}\left(\mathrm{SO}^{\mathrm{O}} \mathrm{C}_{5} \mathrm{H}_{27}\right. \\
\left(\mathrm{CH}_{3}\right)^{-} \mathrm{C}^{-17}\end{array}$ & $\begin{array}{l}6.0 \\
5.7\end{array}$ \\
\hline $\begin{array}{l}\text { Phenol } \\
\text { Phosphine } \\
\text { Potaesium }\end{array}$ & $\begin{array}{l}\mathrm{C}_{6} \mathrm{~K}_{5} \mathrm{OH} \\
\mathrm{PH}_{3} \\
\mathrm{~K}\end{array}$ & $\begin{array}{l}6.2 \\
2.6 \\
3.6\end{array}$ \\
\hline Propare & $C_{3} H_{8}$ & $\begin{array}{c}4.2 \\
3.7 \\
3.7 \text { 10 } 3.9 \\
3.6\end{array}$ \\
\hline $\begin{array}{l}\text { Propene oxide } \\
\text { Propene: }\end{array}$ & $\mathrm{C}_{3} \mathrm{H}_{6} \mathrm{O}$ & 3.9 \\
\hline n- & $n-C_{3} 3_{6}$ & $\begin{array}{c}3.3 \\
3.2103 .7\end{array}$ \\
\hline eyelo- & $\mathrm{Cy}-\mathrm{C}_{3} \mathrm{H}_{5}$ & 3. 6 \\
\hline Rubidium & Rb & $\begin{array}{l}1.3 \\
3.6\end{array}$ \\
\hline $\begin{array}{l}\text { Silver perehlorate } \\
\text { Sodium }\end{array}$ & $\begin{array}{l}\mathrm{AgClO}_{4} \\
\mathrm{sis}\end{array}$ & 3.0 \\
\hline Starnie jodide & Snl, & 6.7 \\
\hline Sullur dioxide & $\mathrm{SO}_{2}$ & $\begin{array}{l}2.1 \\
2.3\end{array}$ \\
\hline Sulfur hexaljortae & $s \Sigma_{6}$ & $\begin{array}{l}2.3 \\
2.3\end{array}$ \\
\hline $\begin{array}{l}\text { Toluene } \\
\text { Trinitrobenzene }\end{array}$ & $\mathrm{C}_{6} \mathrm{H}_{5} \mathrm{CH}_{3}$ & $\begin{array}{l}6.8 \\
9.0\end{array}$ \\
\hline Trinitrobenzene & & \\
\hline Water & $\mathrm{H}_{2} \mathrm{O}$ & $\begin{array}{r}1.1 \\
1.0 \\
.8\end{array}$ \\
\hline Xenon & Xe & $\begin{array}{l}=3 \\
\pm .2 \\
\therefore .3\end{array}$ \\
\hline $\begin{array}{l}\text { Xylene: } \\
\text { o- }\end{array}$ & $0-C_{6} H_{i}\left(\mathrm{CH}_{3}\right)_{2}$ & -.8 \\
\hline p- & $\mathrm{p}-\mathrm{C}_{8} \mathrm{H}_{4} \mathrm{CCH}_{3} \mathrm{i}_{2}$ & 7.9 \\
\hline
\end{tabular}


NATIONAL SINCHROTRON LIGHT SOURCE

TECHNICAI SPECIFICATION

for

UHV BAREABLE FLANGES

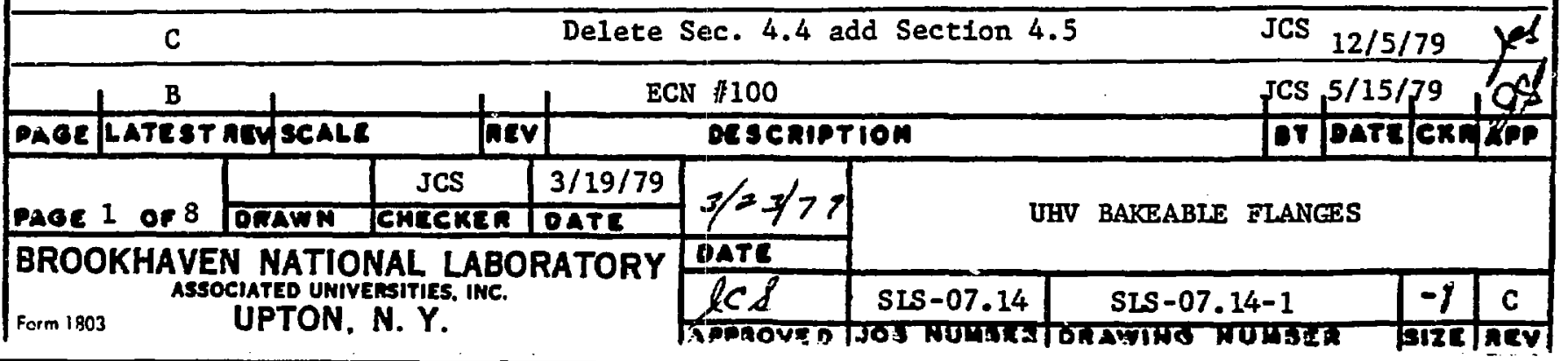


TABLE OF CONTENTS

$\begin{array}{ll}1.0 & \text { Introduction } \\ 2.0 & \text { Applicable Documents } \\ 3.0 & \text { Requirements } \\ 4.0 & \text { Test and Inspection }\end{array}$

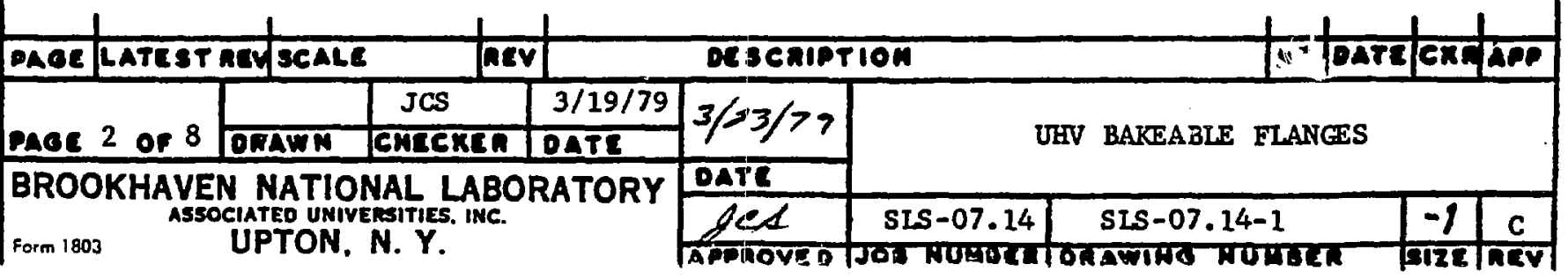


1.0 Introduction

This specification outlines the requirements of the Ultra High Vacuum (UHV) flanges for use on the National Synchrotron Light Source (NSIS) vacuum system.

The flange specified is the Conflat ${ }^{(1)}$ flange, a patented design of Varian Associates and licensed by them to a number of vacuum manufacturers for fabrication.

\subsection{Applicable Documents}

The applicable provisions of the following documents of issue in effect on the effective date of award shall become a part of this specification, to the extent specified herein.

1. AVS 3.2-1965 "Flanges Bakeable to $500^{\circ} \mathrm{C}$. American Vacuum Socfety, 335 E. 45th St., New York, N.Y. 10017

2. ASTM A-182 "Forged - - Parts for H1 Temperature Service".

3. Federal Specification $Q Q-S-763 d$ "Steel Bars, Shapes and Forgings, Corrosion Resisting."

4. MIL-S-862B "Steel - - Billets, Corrosion Resisting: Reforging Application."

5. ASTM E-112 "Estimating the Average Grain size of metals."

6. ASTM E45-75 "Determining the Inclusion Content of Steel."

\subsection{Requirements}

The proposed vendor must be able to substantiate his technical capability which qualify him to produce UHV flanges to this specification. One Important factor is recent experience in successful production of quantities of URV flanges. Other factors to be considered are Quality Assurance and Inspection operations and machine tool capabilities for producing a volume flow of flanges.

\subsection{Seal Design}

All flanges made to this specification shall be of the knife edge design (Conflat) which uses a flat circular copper gasket to effect a leak tight, bakeable seal. Flanges are to be manufactured according to the Varian drawings wich are provided as part of the license agreement.

(1) Conflat is a registered trademark of Varian Associates.

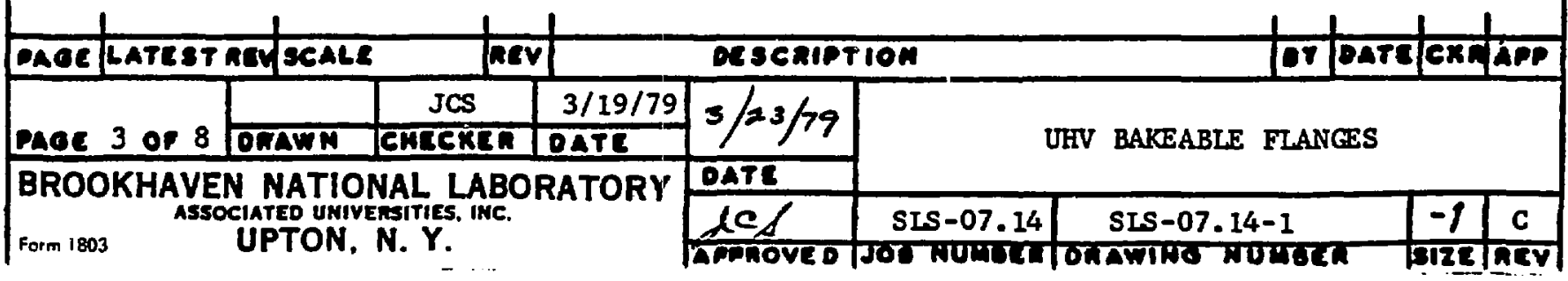




\subsection{Raw Material}

A. All flanges are to be made from certifled type 304 stainless steel.

B. All flanges are to be manufactured from cross-forged (blanks), or vacuum remelted bars (Consumable Electrode Remelting). The crossforged blanks are to be cut from billets certified to ASTM A-182 chemistry and federal specification QQ-S-763 d. If such material is not readily available, vendor may use, upon approval of NSIS, billets certified to MIL-S-862 B Class I (304) for reforming purposes.

The vacuum remelted bars are to conform to federal specification QQ-S-763d.

C. Typical certifications for all the above materials which are used in manufacturing flanges must be furnished to NSLS. As a minimum, each certificate shall state:

1. The heat number of the melt.

2. The purchasers name, order number and date.

3. A description of the material including the specification to which it is made.

4. The results of chemical analysis reporting all elements listed in the specification for that alloy.

5. The results of physical tests of mechanical properties for hardness, ultimate tensile strength, gield strength and percent elongation.

\subsection{Forgings}

A. Flanges and flange parts which are required to be made from forgings must be formed by a process referred to as "Cross-Forging". This process is performed by hammer forging each plece triaxially at a "hot-cold work" temperature, approsimately $1800^{\circ} \mathrm{F}$.

Billets from which forging blanics are cut have predominantly longitudinal metal flow due to drawing out to length in forging or roling. In order to obtain finished flanges free fxom these potential leak paths the metal must receive $100 \%$ work and complete recrystallization to obtain the necessary fine grain structure.

The final operation for solid flanges and inserts is to hammer the plug into a Pocket Die (of larger diameter) causing the metal to reflow outward and fill the die. For rings to be used as retainers for rotatable Inserts, the final operation is hamering into a ring die which produces the proper I.D. and O.D. and a center punch out blank

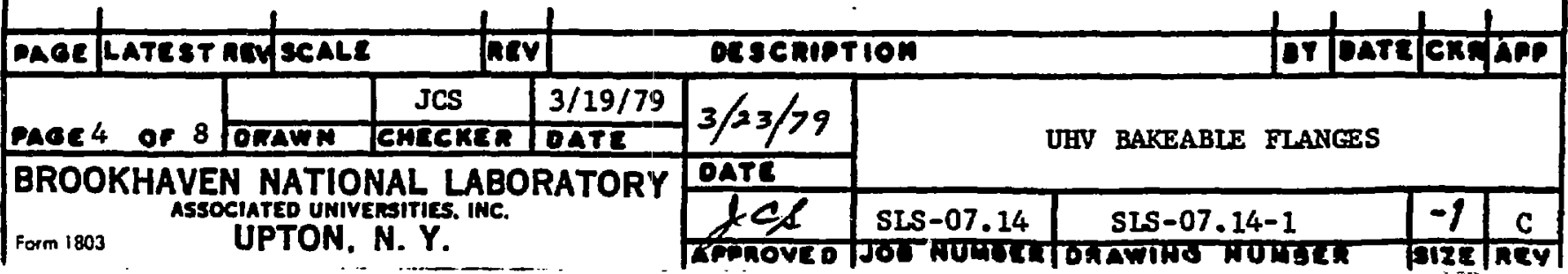


which is discarded.

The finished forging should have at least a No. 2 grain size in the smaller flanges and no more than a No. 6 in larger sizes. Refer to ASTM E-112 for explanatory information.

\section{B. Heat Treatment}

Forged blanks shall be stress relief annealed at $1975^{\circ} \mathrm{F}$ prior to rough machining. Time at temperature and method of cooling depend on section thickness and shall be chosen to achieve optimm properties. Certification of heat treatment including time, temperature and quench shall be provided at the request of NSIS.

c. Machining.

Following forging and heat treatment, each piece shall be rough machined using only "sulphur free" cutting flulds. The use of abrasive paper, buffing compounds or grinding wheels is prohibited in any finishing operation.

D. Hardness

A hardness test shall be performed by the vendor on rough machined forgings in the annealed condition. All flanges mast be certified to be a minfmum hardness of Rockwe11 B 80 throughout. Typically, flanges should all be in the range of Rockwell B-85 to 90 which is the most desirable. The maximum hardness allowable is Rockwell B-95.

E. Permeability

In the annealed condition the magmetic permeability of each forging shall not exceed 1.15 at 200 Oersted, (alr equal to 1.00). Magnetic permeability of austenitic stainless steel is a function of the amount of free ferrite present in the alloy. The maximum ferrite allowed shall be 1.5\%. Any flange which when tested indicates ferrite exceeding $1.5 \%$ shall be rejected.

\section{F. Cleaning and Handling}

Prior to final inspection, each flange shall be chemically cleaned by vapor degreasing in tricholorethane followed by an alkaline soak cleaner, a thorough tap water rinse and drying with warm, oll-free alr or dry nitrogen. Movement of fintshed flanges frcm machining to cleaning and inspection shall be within protective handing contalners, made specifically for this purpose.

\begin{tabular}{|c|c|c|c|c|c|c|c|c|c|c|c|c|}
\hline Das 1 & ATEST & nOY SCALE & her & & orsenipy & 100 & & & 07 & DATE & CRF & APP \\
\hline & & & JCS & $3 / 19 / 79$ & & & \multirow{3}{*}{ UHV } & \multirow{3}{*}{ BAKEABLE } & \multirow{3}{*}{\multicolumn{2}{|c|}{ FLANGES }} & & \\
\hline MaE 5 & or 8 & Dhamn & CHLERLA & DATE! & & & & & & & & \\
\hline \multirow{2}{*}{\multicolumn{5}{|c|}{$\begin{array}{l}\text { BROOKHAVEN NATIONAL LABORATORY } \\
\text { ASSOCIATED UMIVESITIES. INC. } \\
\text { UPTON. N. Y. }\end{array}$}} & DATE & & & & & & & \\
\hline & & & & & $\frac{c c \alpha}{\text { tenoven }}$ & SIS-07.14 & & SIS-07.14 & & & $\frac{-1}{\pi x}$ & C \\
\hline
\end{tabular}


The bar stock from which flanges are made shall be procured and tested by the vendor according to the following procedures:

A. Alloy deslgnated shall be AISI type 304. Bars shall be purchased as and certified as conforming to federal Specification QQ-S-763d Indicating the condition desired either $A$ or $B$.

B. The magnetic permeablitty of bar stock shall be the same as for forgings, refer to Sec. $3.3 \mathrm{E}$.

c. The hardness of the bar stock shall be the same as for forgings (see Sec, $3.3 \mathrm{D}$ ) except that measurements shall be taken on the face of the bar at a diameter equal to one half the radius and outward. Finished flanges must meet the minimum hardness requirements in the area of the knife edge seal.

D. The vendor shall be responsible for the testing of the bar stock conformance to the microscopic examination and helium leak test as outlined below.

E. Coupon samples shall be the same diameter as the bar from which they are taken, shall be $3 / 8$ inch thick $\pm 1 / 8$ inch and be taken perpendicular to the longltudinal axis of the bar. One sample from each end of bar.

F. All samples shall be machined to .062 in thickness and have a surface finish sultable for the macroscopic examination spectfied below. Identify each coupon with respect to specific bar.

G. Test the sample for hardness and record the result.

H. Prepare samples for macroscople examination as follows: Samples shall first be heated in water to the same temperature as the following acid etching solution. Samples shall be Lmersed in a solution consisting of equal parts, by volume, of concentrated hydrochloric acid and vater at approximately 160 Degrees $F$. for a period of time sufficient to develop fully the macro structure. Fresh acld shall be used for each lot of samples. After etching, the samples shall be washed in running tap water and any deposit removed by scrubbing. The sample shall then be dipped in cold concentrated nitric acid, washed in cold tap water and dried. After etching, the grain structure shall be examined with a 30 power microscope. Results are to be incerpreted by a metallurgist. There should be no evidence of pipes, bursts, segregations, porosity, looseness, seams, pinholes, cracks, non-metallic inclusions, or any other defects which detrimentally affect its suitability for the service intended.

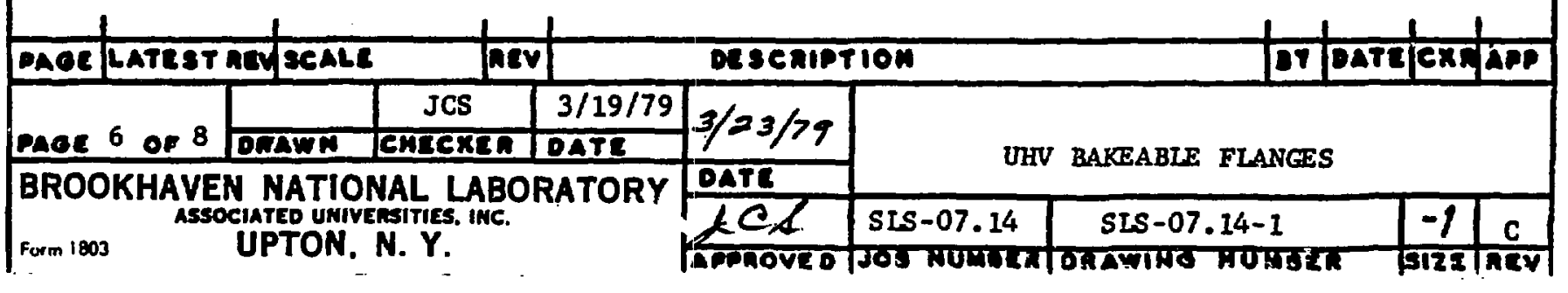


Results of this microscopic examination shall follow the requirements of ASTM F-45-75 for "Microscopical Methods". Should this test reveal defects which are judged to be injurious or even questionable in terms of its use for UHV flanges, the bar shall be rejected.

I. Following the macroscopic examination, each coupon that is accepted thus far will be helium leak tested as follows:

1. Chemically clean each piece first by vapor degreasing in trichloroethane followed by 15 min. ultrasonic cleaning in methanol.

2. Bake Coupon(s) at $250^{\circ} \mathrm{C}$ for 4 hours in air or inert atmosphere.

3. Leak test on mass spectrometer hellum leak detector. Maximum leak rate for hellum $2 \times 10^{-10} \mathrm{std} . \mathrm{cc} / \mathrm{sec}$.

4. If the coupon from elther end of a bar falls any of the above tests, the entire bar from which the sample was taken will be rejected. If $20 \%$ of the coupons from the bars of a given melt fall the test, the entire melt is rejected.

5. All coupons must be retained by the vendor until such time as bars have been used for production of flanges. Records of traceability of all accepted bars by Purchase Order number, bar number, date and heat number shall be kept by the vendor.

\subsection{Finishing Bar Stock Flanges}

Final machining, cleaning and handling of fianges made from bar stock shall follow the same requirements as for forged flanges.

\subsection{Final Acceptance}

Final acceptance of all flanges shall take place following delivery to, and inspection and testing by NSLS.

\subsection{Pre-Award Inspection}

NSIS reserves the right to send representatives to prospective vendor's plant prior to award for the purpose of inspecting the manufacturing facilities and reviewing the quality assurance organization. Vendor shall be prepared to respond to inquiries regarding the information provided in section 4.1 and such other sections of the specification pertinent to determining the qualifications of the prospective vendor.

\subsection{Source Inspection}

A deslgnated NSIS representative shall be permitted to witness any or all of the test and inspection provisions herein required. When so requested, the vendor shall notify NSIS 48 hours prior to the performance of a given test or inspection. In addition, NSIS reserves the right to inspect any other process of procurement or manufacturing pertaining to these flanges including forgings which may be made by a sub-contractor.

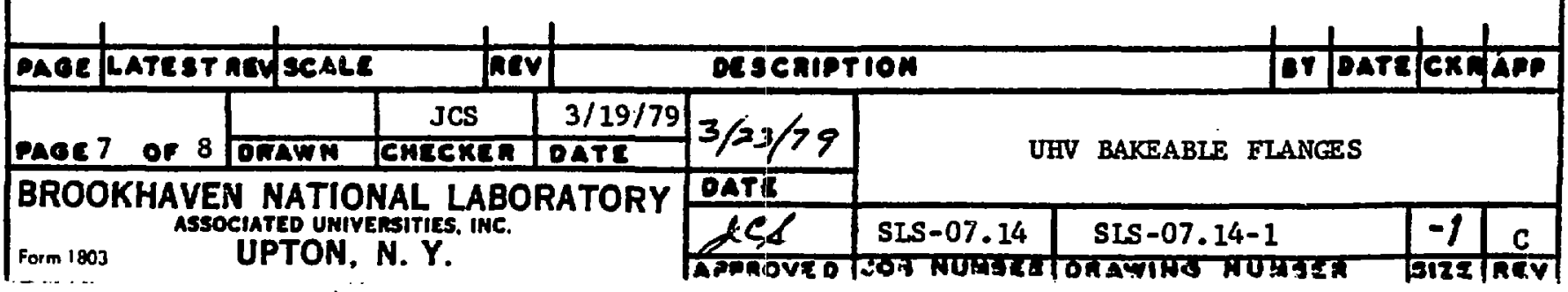


4.3 Iange Inspection

In addition to the requirements of other seetions all flanges, after being chemieally cleaned, shall be $100 \mathrm{z}$ visually inspected for defects in surface finlsh and damage to the seal surface.

4.4 Deleted

4.5 Certification of Compliance

If the certifleations specified in Seetion $3.2 \mathrm{C}$ are not avallable, then an original certifieation by the vendor (seller), stating that the flanges supplied meet this specification, will be acceptable.

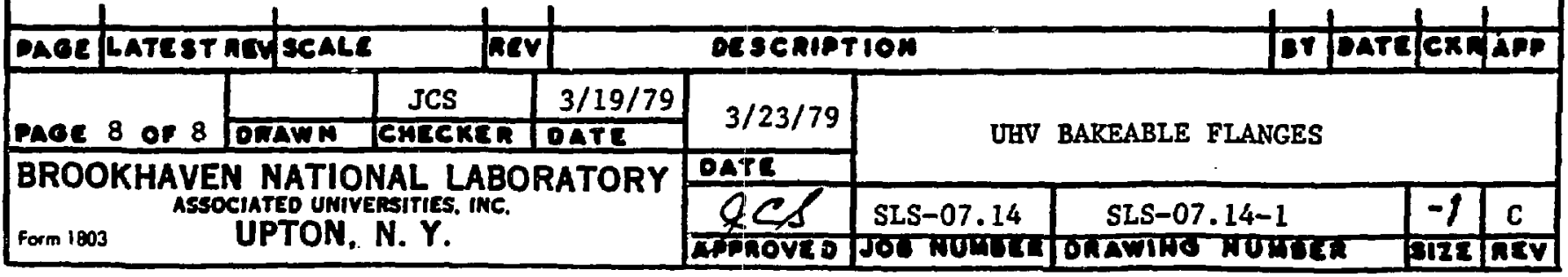


NATIONAL SYNCHROTRON LIGHT SOURCE

TECHNICAL SPECIFICATION

for

COPPER GASKETS FOR CONFLAT FLANGES

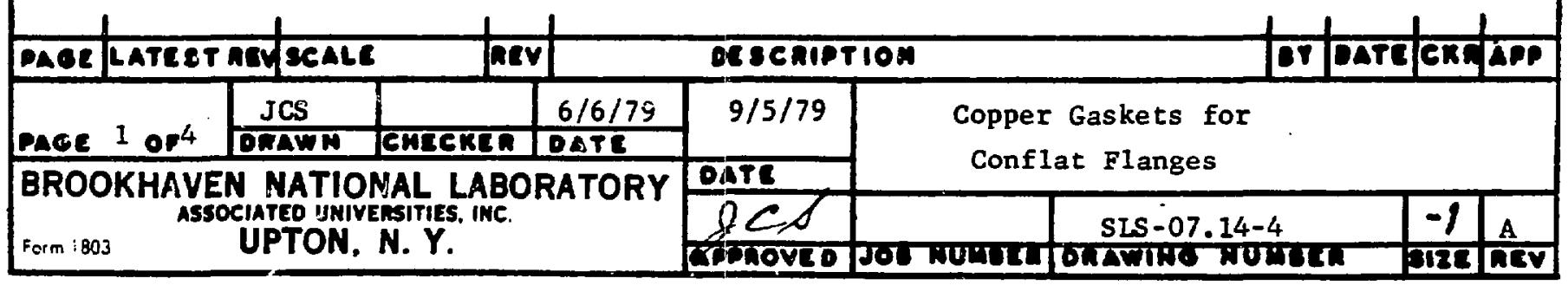




$\begin{array}{ll}1.0 & \text { General } \\ 2.0 & \text { Material } \\ 3.0 & \text { General Surface Quality } \\ 4.0 & \text { Chemical Composition } \\ 5.0 & \text { Size Tolerance } \\ 6.0 & \text { Packaging }\end{array}$

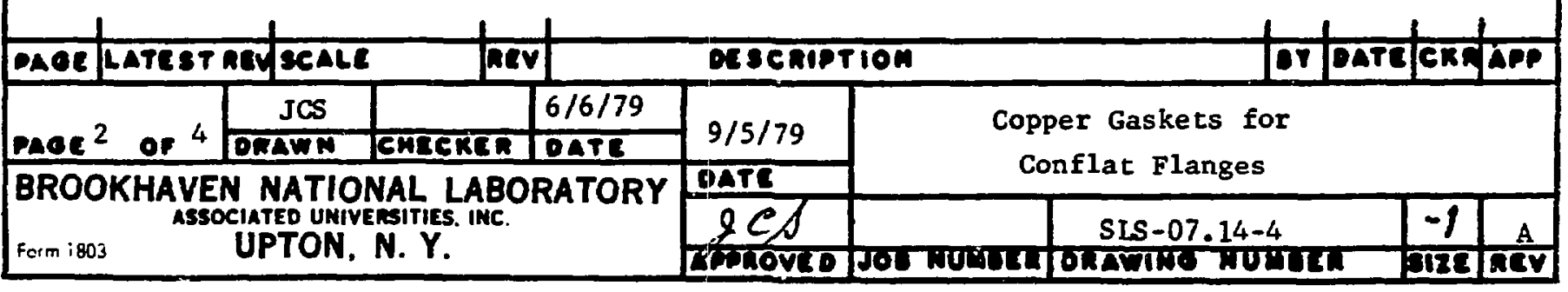




\subsection{General}

1.1 This specification describes the copper gasket that is to be used with the UIV Conflat* flanges.

\subsection{Materlal}

2.1 Material to be electronic grade certified oxygen-free high conducting (OFIC) copper. (Copper alloy \#101 Oxygen free electronic).

\subsection{General Surface Quality}

3.1 All surfaces shall be uniformly bright and free from excessive cracks, folds, die marks, laps seams, pits, galls, blisters, and foreign contamination. In general, all defects which exceed $2 \%$ of the stock thickness or 0.020 inch, whichever is smaller, shall be deemed excessive. Additionally, the following shall apply to the specific forms indicated:

3.2 Electrical Resistivity - The electrical resistivity of specimens when annealed at $500^{\circ} \mathrm{C}$ for 30 minutes in a hydrogen or other reducing atmosphere shall not exceed $0.15176 \mathrm{ohm}-\mathrm{g} / \mathrm{m}^{2}$ at $20^{\circ} \mathrm{C}$ corresponding to a conductivity of not less than 101 percent International Annealed Copper Standard in accordance with ASTM method B 193, Test for Resistivity of Electrical Conductor Materials.

\subsection{Temper}

OFHC Copper

$1 / 4$ - hard
Typical Rockwell Hardness

$\begin{array}{cc}\text { F-Scale } & 30 \text { T-Scale } \\ 70 & 36\end{array}$
Typical

Yield Strergth

at $1 / 2 \%$ - PSI 30,000

\subsection{Chemical Composition}

4.1 Chemical Limits - The material shall conform to the following chemical composition or refiner's certified analysis:

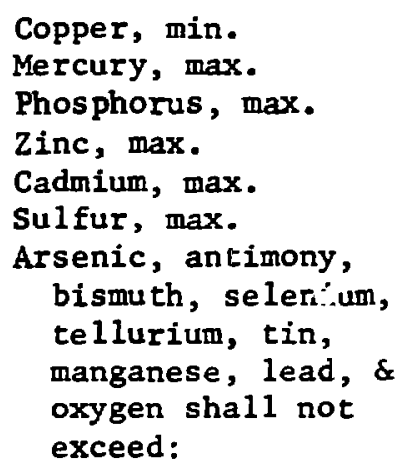

* Registered trademark of Varian Associates.

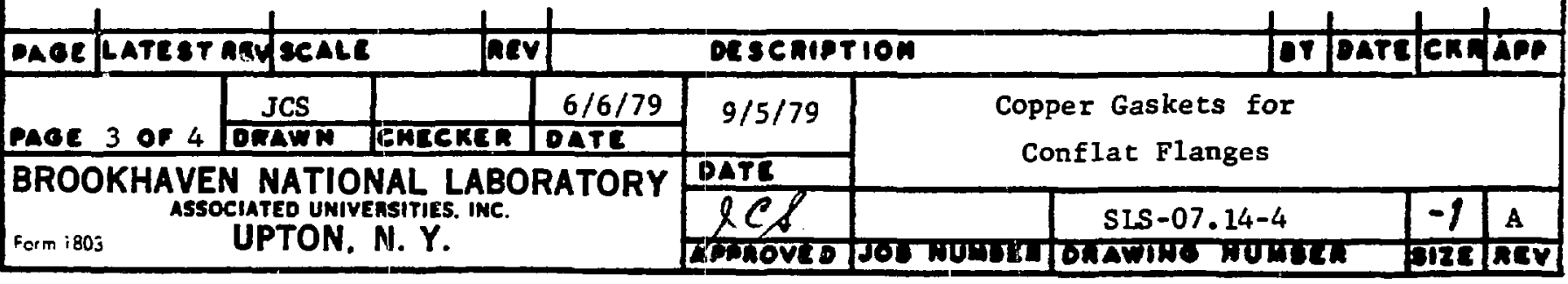


Copper shall be determined by difference of "Impurity Total" from

100\%. "Impurity Total" is defined as the sum of silver, sulfur, lead, tin, bismuth, arsenic, antimony, iron, nickel, mercury, zinc, phosphorus, selenium, tellurium, manganese, cadium, oxygen.

\subsection{Size Tolerance}

\begin{tabular}{|c|c|c|c|c|}
\hline & & Thickness & O.D. & I.D. \\
\hline $\begin{array}{l}953-5070 \\
953-5014 \\
953-5013 \\
953-5015 \\
953-5016 \\
953-5017\end{array}$ & $\begin{array}{l}\text { for Mini ConFlat Flanges } \\
\text { for } 23 / 4^{\prime \prime} 0 . D \text {. ConFlat Flanges } \\
\text { for } 33 / 8^{\prime \prime} 0 . D \text {. ConFlat Flanges } \\
\text { for } 4 \frac{1}{2} " 0 . D \text {. ConFlat Flanges } \\
\text { for } 6 " 0 . D \text {. ConFlat Flanges } \\
\text { for } 8^{\prime \prime} 0 . D \text {. ConFlat Flanges }\end{array}$ & $\begin{array}{l}.080 \pm .0035 \\
.080 \pm .0035 \\
.080 \pm .0035 \\
.080 \pm .0035 \\
.080 \pm .0035 \\
.080 \pm .0035\end{array}$ & $\begin{array}{l}.838 \pm .001 \\
1.895 \pm .001 \\
2.423 \pm .001 \\
3.243 \pm .001 \\
4.743 \pm .001 \\
6.743 \pm .001\end{array}$ & $\begin{array}{l}.640 \pm .003 \\
1.451 \pm .003 \\
2.010 \pm .003 \\
2.506 \pm .003 \\
4.006 \pm .003 \\
6.007 \pm .003\end{array}$ \\
\hline
\end{tabular}

\subsection{Packaging}

6.1 All gaskets shall be packaged with protective material to prevent damage and contamination during shipment.

Additionally, each gasket shall be individually fuil packaged and heat sealed to insure contaminate free shelf life.

NOTE: The standard Varian copper gasket meets this specification.

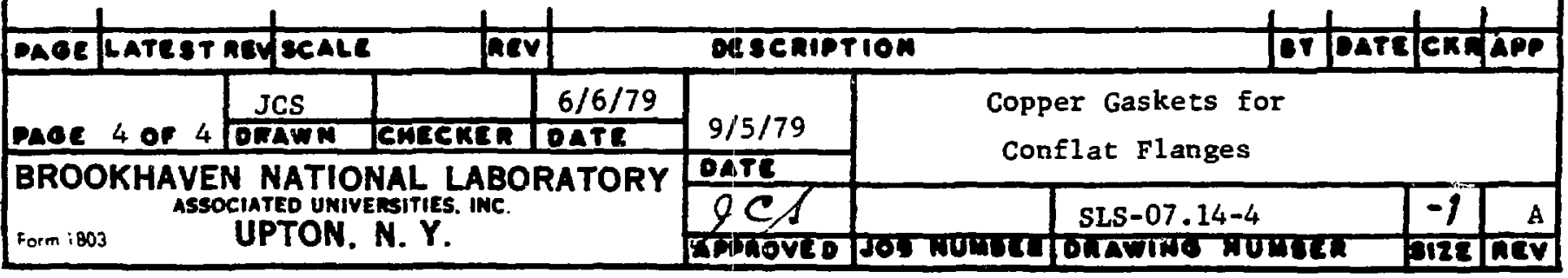




\section{VACUUM PROCEDURE*}

OPEN VUV OR X-RAY FRONT END VALVE

TO RING

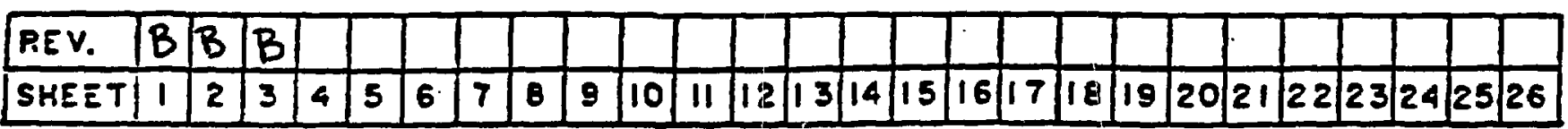


1. Scope

Procedure to allow beam lines to be opened to ring with minimum negative effects.

2. Documentation, Materials, and Equipment

2.1 "Policy for NSLS utilization by Participating Research Teams".

2.2 "Requirements and Guidelines for NSLS Experimental Beam Line Vacuum Systems" BNL 28073. Note: Memo 3/11/85 discontinue use of fomblin oil and grease.

2.3 Calibration factors for ionization gauge (IG) and RGA parent peaks.

2.4 RGA system.

2.5 Nude I.G. and controller.

2.6 SLS-07.19-4-1 Vacuum procedure for baking out VUV or X-ray ring.

3. Special Instructions

3.1 To open front end valve to ring the following vacuum requirements must be met.

a. Instrument tee I.G. must indicate $2 \times 10^{-9}$ Torr or less after correcting for calibration factor.

b. The RGA scan must indicate the predominant gas component to be hydrogen and it must be a minimum of $60 \%$ of the total pressure.

c. There shall be no evidence of leaks (external, virtual, etc.) in the system, air or other.

d. High masses, greater than 28 shall be less than $10 \%$ of the total pressure.

e. Hydrocarbons, fluorocarbons, and other gas components indicated at mass locations $38,41,43,45$ and greater shall total less than $1 \times 10^{-11}$ Torr.

f. If instrument tee I,G. indicates $9 \times 10^{-10}$ Torr or less then a RGA scan is not required $(b, c, d, e)$ to open.

3.2 Any exception to 3.1 must be approved by C. Foerster or H. Halama. 


\section{Setup}

4.1 Beam line vacuum systems which are valved to front end vacuum shall be constructed of materials and techniques as outlined in 2.1 and 2.2

4.2 System components should be vacuum aked and conditioned using 2.6 Vacuum Procedure as a guide. Conditioning must include $\mathrm{ArO}_{2}$ glow discharge cleaning of surfaces which will be subject to beam induced. desorption.

4.3 Ion gauge and RGA should be degassed after system conditioning and a minimum of 48 hours prior to system evaluation for front end valve opening.

4.4 Opening of front end to ring valve for first light may only be performed during low beam current operation. Some low beam conditioning is required to prevent excessive pressure. Vacuum group should aiways be notified and represented.

\section{Procedure}

5.1 Record I.G. reading from instrument tee attached to beam line side of front end to be opened.

5.2 If gauge reading is acceptable, run RGA scan on $10^{-9}$ and $10^{-11}$ ranges. RGA must be degassed and "stabilized" prior to this operation.

a. Multiplier to be set to farday cup reading on mass 28 (calibration).

b. Record on upper right of scan

1. Date and time

2. Front end number

3. Valve status

4. Ion gauge reading

5. RGA total pressure readings

c. Record scale next to each mass scan

5.3 If scans are acceptable per 3.1, vacuum permission is given to open valve.

5.4 If scans are not acceptable, Vacuum Group will advise corrective action.

5.5 When valve is opened monitor pressure and rescan RGA with beam in front end.

a. Record beam current and beam life on scan. 
VACUUM PROCEDURE

FOR

BAKING OUT VUV OR X-RAY STORAGE RING

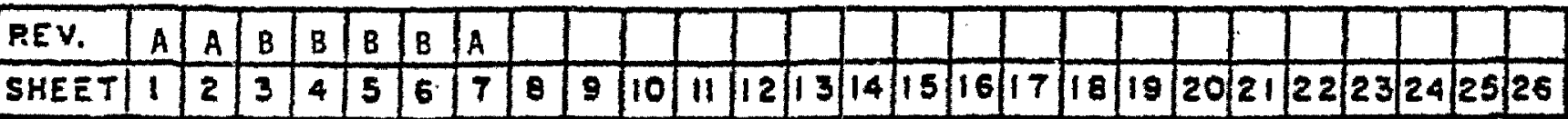




\section{Scope}

This bakeout procedure encompasses the nitrogen purge, pump down, leak test, bakeout, and conditioning of all pumps, gauges, and residual gas analyzers. in the VUV or X-Ray storage ring.

2. Equipment and Materials

2.1 Liquid nitrogen boil off supply

2.2 Megasorb pumping station

2.3 Liquid nitrogen

2.4 Turbomolecular pumping station

2.5 Helium leak detector

2.6 Helium supply

2.7 Helium calibrated leak

2.8 Flexible bellows line

2.9 White gloves

\section{Set-Up}

3.1 Drain water from chamber and all TSP pumps.

3.2 Start-up leak detector and calibrate to manufacturers specification. Record sensitivity.

3.3 Connect megasorb pumping station to ring roughing valve using flexible bellows line (wear white gloves). Charge cryosorption pump with liquid nitrogen.

3.4 Connect turbomolecular pumping (TMP) station to ring roughing valve using flexible bellows line, (wear white gloves). Start TMP.

3.5 Connect leak detector to foreline of turbomolecular pumping station.

3.6 Switch on cryosorption roughing pump. 
* See Fig. 1 for sequence and approximate vacuum bake conditiong cycle.

4.1 Pre-bakeout leak test:

a. Pumpdown ring with megasorb pump. Carbon vane pump is turned on and system is pumped for 20 minutes. Stage one is used to pump the system down to 500 microns. Valve off stage one, and valve in stage two. Pump to 5 microns.

b. When ring pressure reacties 5 microns valve in turbomolecular pump and valve off megasorb pump.

c. When ring pressure is equal to or less than $10^{-5}$ Torr leak check ring.

4.2 Venting with liquid nitrogen boil of :

a. Connect copper venting line to yent valve. Before connecting, bakeout line with heating tape for one hour at $125^{\circ} \mathrm{C}$. Purge line with nitrogen during bakeout.

b. Slowly open vent valve and vent ring. Vent at a rate comparable to pumpdown rate to avoid stirring up particulate matter and causing undue stresses on chamber.

4.3 Nitrogen Purge and Bakeout Start:

a. Stari purging ring with nitrogen boil off before starting bake out cycle. Turn on purge gas manifold heater to raise the nitrogen gas temperature to $125^{\circ} \mathrm{C}$ at a flow rate of $53 \mathrm{ft}^{3} / \mathrm{hr}$. Turn on all ring pump and chamber heaters when starting to purge. Bake aluminum chamber at $125^{\circ} \mathrm{C}$ and the stainless steel parts up to $250^{\circ} \mathrm{C}$. Continue to purge for one hour.

b. Valve off purge gas. Start pump down with megasorb pump. Carbon vane pump is first valved in for about 20 minutes. Stage one is then used to pump down to 500 microns. At 500 microns valve off stage one and pump to 5 microns with stage two.

c. At 5 microns valve off the megasorb pump and valve in the turbomolecular pump. (This pump had been previously started at the same time as the megasorb, but had been left valved off from the ring.) 


\section{4 -Leak Test at Bake Temperature}

When ring pressure is equal to or less than $10^{-5}$ Torr, leak check ring. Test per procedure.

\subsection{Glow Discharge Condition Ring}

a. Set up Argon 0xygen (90-10) gas on bleed valve adjacent to magnet section to be conditioned.- Purge inlet.

b. Set up protected turbo pumping system on opposite end from bleed, of magnet section to be conditioned.

c. Connect power supply to D.I. pump anode in conditioning section. Insure proper electrical grounding.

d. Set up mass spec. system to monitor gases pumped during conditioning.

e. Adjust bleed valve for a pressure of $20 \mathrm{~m}$ Torr in the section.

f. Turn on and adjust power supply for negative 400 VDC. Next, adjust bleed gas for a current of $300 \mathrm{~mA}$. Run for ten minutes.

g. With supply off, reset for positive voltage. Turn on and adjust current to $300 \mathrm{~mA}$. Run for 20 minutes.

h. Run M/S scan at start and finish of positive conditioning.

i. Repeat 4.5 a through $i$. For sections of ring to be conditioned.

j. RF cavity to be conditioned per procedure when required. 


\subsection{ISP Conditioning:}

When the pressure is equal to or less than $10^{-5}$ Torr condition all Titanium Sublimination Pumps (TSP). Each of the four filaments in the pump is individually degassed at 20 amps for five minutes. At the end of the five minute degas cycle, each filament is run up to 50 amps for 30 seconds then back to zero. After conditioning, the system should be left connected to filament $\# 1$. Record conditioning of each filament in VUV vacuum log book.

4.7 DIP Conditioning:

With pressure equal to or less than $10^{-5}$ Torr condition all Distributed Ion Pumps (DIP's). Dipole magnets must be on for DIP conditioning. The ring ion gauges must be turned on for this conditioning. The dipole magnets are first turned on, then the DIP's are switched on one at a time. Each pump is turned on for 45 seconds and the ion gauge pressure observed. The pressure will rise quite high when the pump is first turned on, but will decrease with each switching on of the pump. Continue this procedure until the pressure no longer increases. Turn off dipole magnets after conditioning the DIP's. Measure pump leakage current with no magnetic field. If pump currents are equal to or greater than $1 \times 10^{-11}$ Torr equivalent pressure, "spark-knock" pumps. Record all leakage currents in vuv vacuum log book.

4.8 SIP Conditioning:

Condition all SIP's following the procedure described in section 4.7 above for DIP's.

4.9 When the DIP's and SIP's are conditioned as outlined, the cryopump connected ti, the ring is introduced into the system. The cryopump must have been previously conditioned, cooled down and ready for operation.

4.10 DIP's and SIP's are turned on one at a time for a final condition check. All DIP's and SIP's are turned off at conclusion of this step. 
4.11. One $\mathrm{TI}$ filament in each cartridge is flashed at $50 \mathrm{~A}$ for $2 \mathrm{~min}$. The filament chosen should follow in numerical sequence, if $\# 1$ is broken

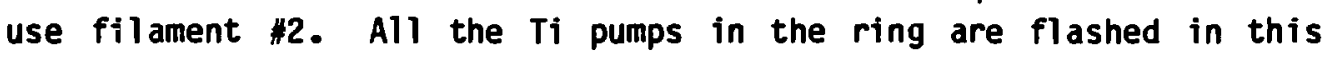
fashion. Care must be taken to bring up each filament to $50 \mathrm{~A}$ slowly.

4.12 Both RGA's and IG's are degassed. Discretion is exercised and if there is a large pressure increase, the degas is terminated until pressure returns to a safe level, then repeated. The IG's are gradually degassed to $40 \mathrm{~W}$ max. This process is continued for a 20 min. period. The RGA controllers incorporate an automatic degass ramping circuit. After degassing the IG and VG mass spectrometers are left on.

4.13 The cryopump is valved off and the ring leak checked.

4.14 After the leak check, the bake is terminated (36-48 hr. bakeout) and the cryopump is valved in to the system.

4.15 All the SIP's are turned on. When the pressure reads equal to or less than $10^{-8}$ Torr the TMP's are valved off.

4.16 Approximately 24 hours after terminating the bakeout the Ti pumps are flashed for the last time follow the procedure as outlined in Step 4.11.

4.17 The pressure is monitored with the IG gauges until equilibrium is achieved. 


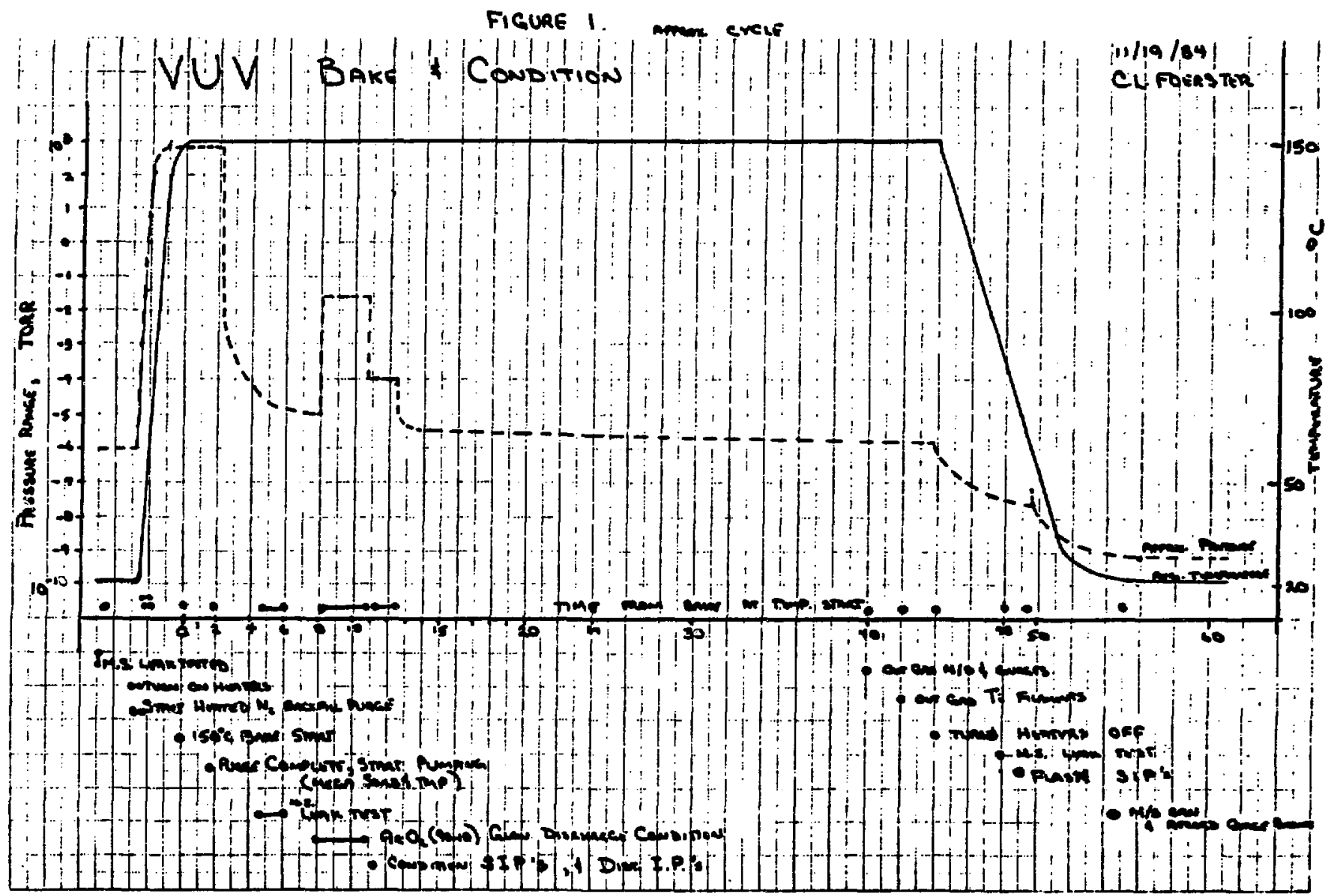

